\title{
The farnesoid $X$ receptor negatively regulates osteoclastogenesis in bone remodeling and pathological bone loss
}

\author{
Ting Zheng ${ }^{1, *}$, Ju-Hee Kang ${ }^{1, *}$, Jung-Sun Sim ${ }^{1}$, Jung-Woo Kim², Jeong-Tae Koh², \\ Chan Soo Shin ${ }^{3}$, Hyungsik Lim ${ }^{4}$ and Mijung Yim ${ }^{1}$ \\ ${ }^{1}$ College of Pharmacy, Sookmyung Women's University, Yongsan-ku, Seoul, Republic of Korea \\ ${ }^{2}$ Department of Pharmacology and Dental Therapeutics, Research Center for Biomineralization Disorders, School of Dentistry, \\ Chonnam National University, Gwangju, Republic of Korea \\ ${ }^{3}$ Department of Internal Medicine, College of Medicine, Seoul National University, Seoul, Republic of Korea \\ ${ }^{4}$ Departments of Physics, Hunter College of the City University of New York, New York City, New York, USA \\ *These authors contributed equally to this work
}

Correspondence to: Mijung Yim, email: myim@sm.ac.kr

Keywords: FXR, osteoclast, RANKL, NFATC1, bone loss

Received: July 18, $2017 \quad$ Accepted: August 09, 2017

Published: August 28, 2017

Copyright: Zheng et al. This is an open-access article distributed under the terms of the Creative Commons Attribution License 3.0 (CC BY 3.0), which permits unrestricted use, distribution, and reproduction in any medium, provided the original author and source are credited.

\section{ABSTRACT}

Farnesoid X receptor (FXR, NR1H4) is a member of the nuclear receptor superfamily of ligand-activated transcription factors. Since the role of FXR in osteoclast differentiation remains ill-defined, we investigated the biological function of FXR on osteoclastogenesis, using FXR-deficient mice. We demonstrated that FXR deficiency increases osteoclast formation in vitro and in vivo. First, FXR deficiency was found to accelerate osteoclast formation via down-regulation of c-Jun $\mathbf{N}$-terminal kinase (JNK) $1 / 2$ expression. Increased expression of peroxisome proliferator-activated receptor (PPAR)Y and peroxisome proliferator-activated receptor gamma coactivator 1 (PGC1) $\beta$ seems to mediate the pro-osteoclastogenic effect of FXR deficiency via the JNK pathway. In addition, we found that FXR deficiency downregulated the expression of interferon- $\beta$ (IFN- $\beta$ ), a strong inhibitor of osteoclastogenesis, via receptor activator of nuclear factor-kappaB ligand (RANKL). We further suggested that interference of IFN- $\beta$ expression by FXR deficiency impaired the downstream JAK3-STAT1 signaling pathways, which in turn increased osteoclast formation. Finally, FXR deficiency accelerated unloading- or ovariectomy-induced bone loss in vivo. Thus, our findings demonstrate that FXR is a negative modulator in osteoclast differentiation and identify FXR as a potential therapeutic target for postmenopausal osteoporosis and unloadinginduced bone loss.

\section{INTRODUCTION}

Bone is consistently renewed throughout life by the opposing activities of osteoblastic bone formation and osteoclastic bone resorption pathways. Although osteoclasts are required for bone remodeling, excess activity of osteoclasts can lead to various diseases such as periodontal disease, osteoporosis, rheumatoid arthritis, multiple myeloma, and metastatic cancers [1-3]. Osteoclasts are giant multinucleated cells derived from hematopoietic precursors of the monocyte-macrophage lineage. During osteoclastogenesis, bone marrow-derived macrophages (BMMs) differentiate into tartrate-resistant acid phosphatase (TRAP)-positive pre-osteoclasts, which then fuse with each other to form mature osteoclasts [4-6].

Macrophage colony-stimulating factor (M-CSF) and receptor activator of nuclear factor kappa-B ligand (RANKL) provide the two necessary and sufficient signals for osteoclast differentiation. Binding of M-CSF to its receptor, CSF-1R, in osteoclast precursors promotes their proliferation and survival via the activation of kinases such as Src, phospholipase C-gamma (PLC- $\gamma$ ), phosphoinositide 3-kinase $\left(\mathrm{PI}_{3} \mathrm{~K}\right)$, protein kinase $\mathrm{B}(\mathrm{PKB}$, also AKT) and extracellular signal-regulated kinase $1 / 2$ 
(ERK1/2) [7-9]. RANKL binding to RANK induces the association of RANK with tumor necrosis factor receptorassociated factor 6 (TRAF6), which activates nuclear factor-kappaB $(\mathrm{NF}-\kappa \mathrm{B})$ and mitogen-activated protein kinases (MAPKs; ERK1/2, p38, and stress-activated protein kinase/c-Jun N-terminal kinase (SAPK/JNK)). In turn, these kinases activate nuclear factor of activated $\mathrm{T}$ cells (NFATc1), the master transcription factor responsible for osteoclast differentiation and function [10].

The farnesoid $\mathrm{X}$ receptor (FXR, NR1H4) is a member of the nuclear receptor superfamily of transcription factors that regulates multiple biological processes. Bile acid has been identified as endogenous ligands for FXR [11-13]. Upon ligand-induced activation, FXR binds to FXR response elements [14] either as a monomer or as a heterodimer with the retinoid $\mathrm{X}$ receptor (RXR) $[13,14]$ and modulates bile acids, lipid and glucose metabolism, inflammation, and energy metabolism $[11,12]$. Given all of these benefits, FXR has been considered as a therapeutic target for the treatment of metabolic disorders $[19,20]$.

Several studies suggest that FXR has complex roles in the pathogenesis of metabolic dysfunction, and its activity in different tissues could possibly exert different effects on metabolism [11-20]. We previously demonstrated that the deletion of $\mathrm{FXR}\left(\mathrm{FXR}^{-/}\right)$in vivo resulted in a significant reduction in bone mineral density compared with that in $\mathrm{FXR}^{+/+}$mice [21]. Since the mechanism by which FXR modulates bone metabolism has not been fully explored, we investigated a specific role of FXR in the modulation of osteoclastogenesis and bone loss in vitro and in vivo. Our work demonstrates that FXR could be exploited to prevent the development of osteoclast-associated bone diseases.

\section{RESULTS}

\section{FXR deficiency facilitates osteoclast differentiation}

To explore the functional role of FXR in osteoclast differentiation, we first examined the endogenous expression of FXR in BMMs by RANKL. The mRNA and protein expression levels of FXR were significantly decreased in BMMs by RANKL treatment (Figure 1A, 1B). Thus, we investigated the role of FXR on RANKLinduced osteoclast formation, using an activator and an inhibitor of FXR. Activation of FXR by chenodeoxycholic acid (CDCA) decreased the formation of $\mathrm{TRAP}^{+}$ multinucleated cells (MNCs), whereas inhibition of FXR by guggulsterone significantly enhanced the formation of TRAP ${ }^{+}$MNCs by RANKL (Figure 1C). We next overexpressed FXR in BMMs, using a retrovirus (Supplementary Figure 1). Overexpression of FXR in BMMs significantly inhibited the formation of TRAP $^{+}$ MNCs mediated by RANKL when compared with that in the control vector (Figure 1D). In accordance with these results, overexpression of FXR attenuated the RANKLinduced expression of NFATc1 during RANKL-mediated osteoclastogenesis (Figure 1E). Taken together, these data suggested that FXR has a negative role in RANKLmediated osteoclast differentiation.

To further investigate the role of FXR on osteoclast formation in vivo, we conducted histomorphometric analyses of bone sections from the distal femur of $\mathrm{FXR}^{+/+}$ and $F X R^{-/-}$mice. $F X R$ deficiency increased the number of osteoclasts per bone surface (N.Oc/BS; Figure 1F). Both the number of $\mathrm{TRAP}^{+}$mononuclear cells (N.Mo. $\mathrm{TRAP}^{+}$cells/BS) and multinuclear osteoclasts (N.Mu. $\mathrm{Oc} / \mathrm{BS})$ per bone surface were increased in $F X R^{-/-}$ compared with $F X R^{+/+}$femur (Figure $1 \mathrm{G}$ and $1 \mathrm{H}$ ). $F X R$ deficiency also enhanced the levels of osteoclast surface per bone surface (Oc.S/BS; Figure 1I). These observations indicate that FXR deficiency increases osteoclastogenesis in vivo. Furthermore, the role of FXR in the context of inflammation-induced osteoclastogenesis was examined using the lipopolysaccharide (LPS)-challenged bone loss model. LPS stimulates osteoclast formation in vivo. When LPS was injected into the supra calvaria region of mice, the number of TRAP stained-osteoclasts was markedly increased in the calvaria of $F X R^{-/-}$compared with that of $\mathrm{FXR}^{+/+}$mice (Figure $1 \mathrm{~J}, 1 \mathrm{~K}$ ). Collectively, these results suggest that $F X R$ is a crucial negative regulator of osteoclast differentiation.

\section{FXR deficiency accelerates osteoclast formation via downregulation of JNK $1 / 2$ expression}

To clarify the mechanism of increased osteoclastogenesis by FXR deletion, we performed in vitro experiments, using BMMs isolated from $F X R^{-/-}$and $F X R^{+/+}$mice. We first showed that $F X R^{-/-}$BMMs exhibited more $\mathrm{TRAP}^{+} \mathrm{MNCs}$ by RANKL in a dose-dependent manner, in comparison to $\mathrm{FXR}^{+/+} \mathrm{BMMs}$ (Figure 2A). In addition, when cultured on dentine slices with RANKL, $F X R-/-$ BMMs generated more resorption pits than $\mathrm{FXR}^{+/+}$BMMs, with larger overall area (Figure 2B).

To examine the mechanisms underlying the osteoclastogenic increase in $F X R^{-/-} \mathrm{BMMs}$, we investigated the expression of NFATc1, a key regulator of osteoclast differentiation. There was a higher increase in the expression level of NFATc1 by RANKL in FXR-/BMMs than in $\mathrm{FXR}^{+/+}$BMMs (Figure 2C). Next, we investigated the role of $F X R$ in the regulation of RANKLdependent signaling pathways, including ERK, p38, JNK1/2, NF- $\mathrm{BB}$, and AKT. There was no significant difference in ERK, p38, NF- $\kappa \mathrm{B}$, and AKT activation by RANKL between $\mathrm{FXR}^{+/+}$and $F X R-/-$ BMMs (data not shown). In contrast, JNK $1 / 2$ phosphorylation by RANKL was suppressed in $F X R^{-/-}$BMMs with a substantial change in protein expression (Figure 2D). The reduction of $\mathrm{JNK} 1 / 2$ protein expression in $F X R^{-/}$BMMs was 
due to decreased JNK1/2 mRNA levels (Figure 2E). Modulation of JNK1/2 expression levels was further confirmed by pharmacological activation (CDCA) or inhibition (guggulsterone) of FXR (Figure 2F), and by overexpression of FXR (Supplementary Figure 2). Paradoxically, JNK is known to be critical for RANKL-
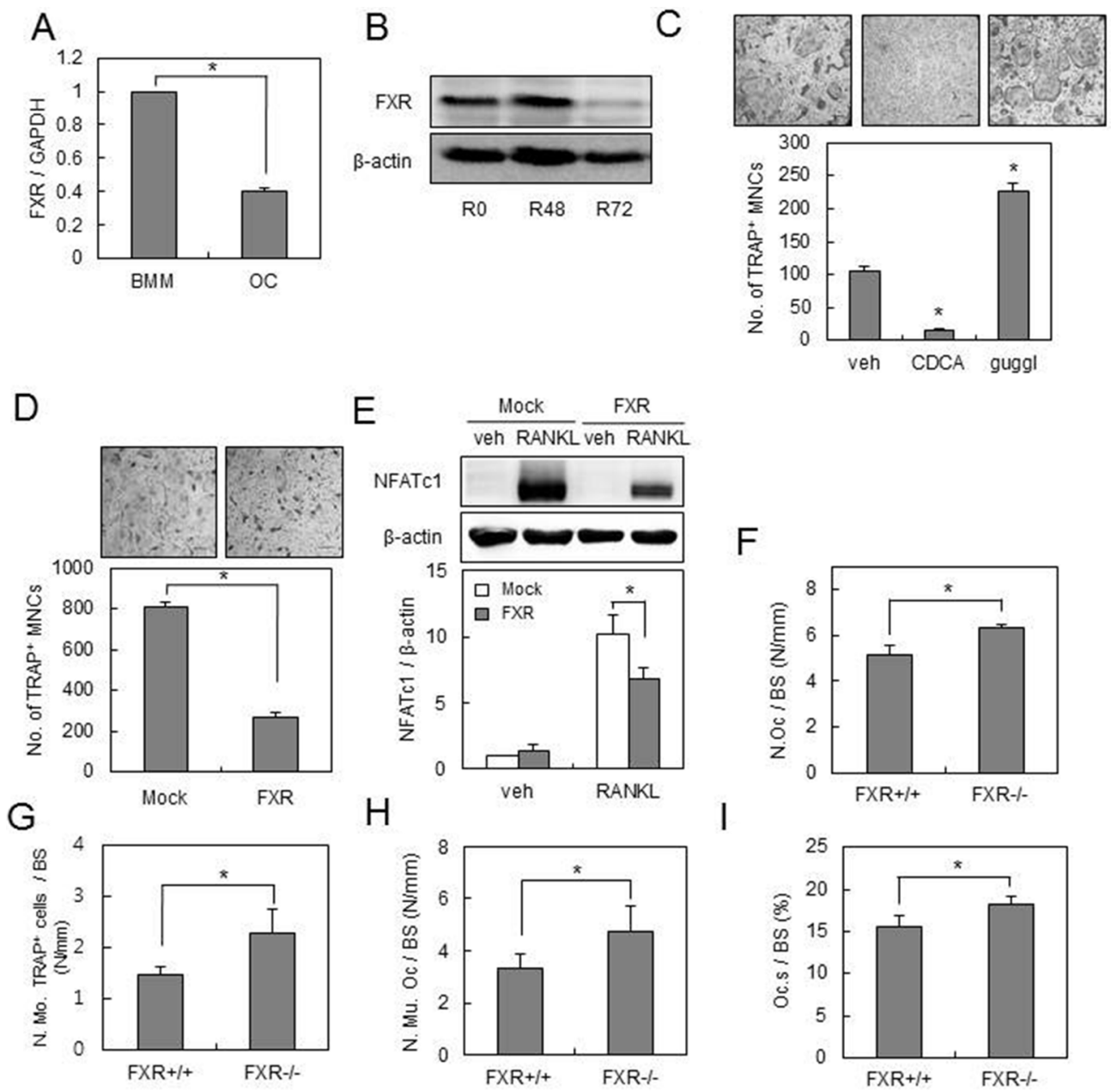

F
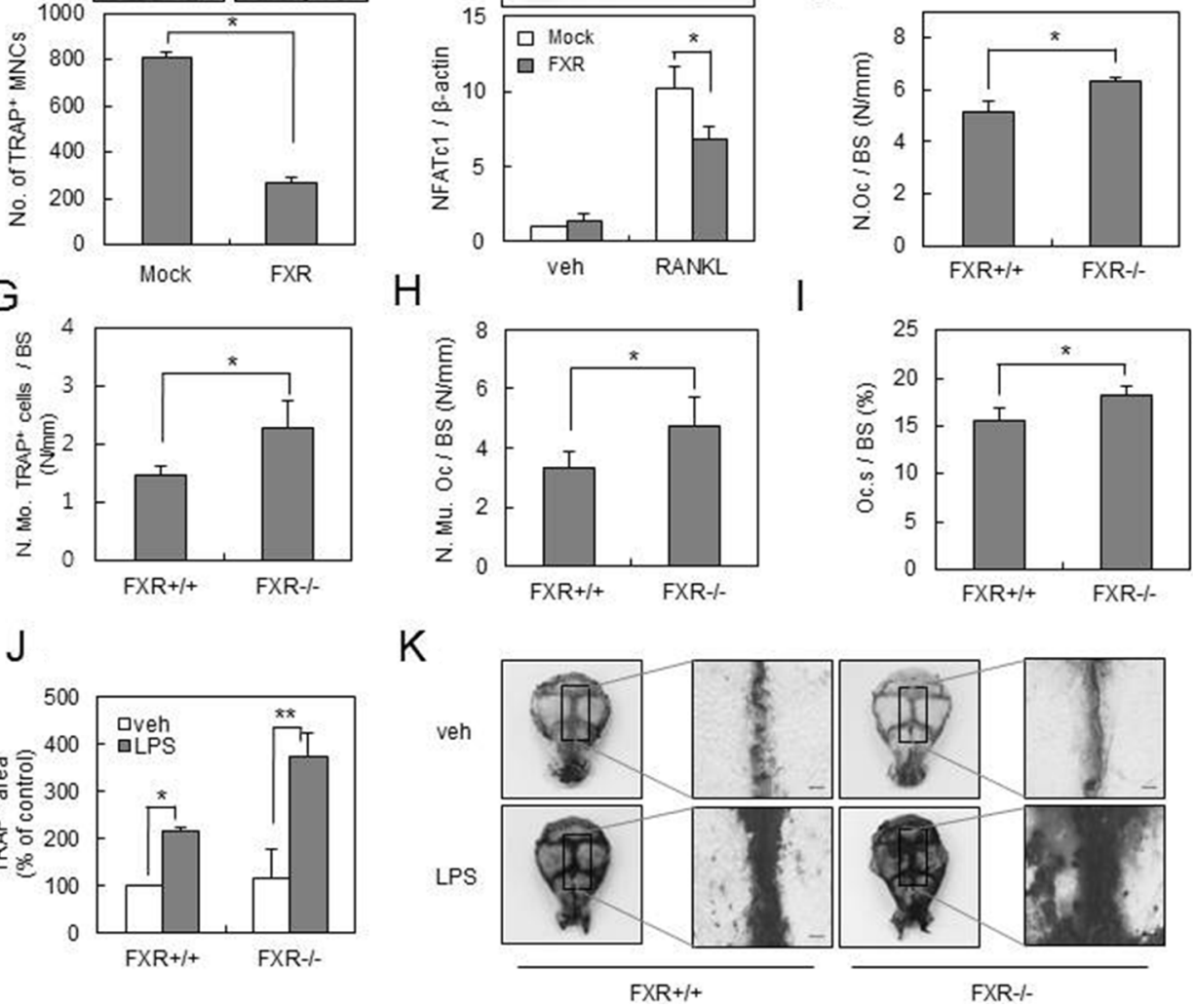

Figure 1: FXR negatively regulates osteoclast formation. (A) BMMs from 12-week-old mice were cultured with RANKL (100 $\mathrm{ng} / \mathrm{ml}$ ) and M-CSF (30 ng/ml) for 4 days. The mRNA levels of FXR were analyzed by real-time PCR. (B) BMMs from 12-week-old mice were cultured with RANKL $(100 \mathrm{ng} / \mathrm{ml})$ for the indicated times and FXR expression levels were analyzed by western blot. (C) BMMs were cultured with RANKL $(100 \mathrm{ng} / \mathrm{ml})$ and M-CSF $(30 \mathrm{ng} / \mathrm{ml})$ in the presence of $75 \mu \mathrm{M}$ CDCA or $0.3 \mu \mathrm{M}$ guggulsterone for 4 days. $\mathrm{TRAP}^{+}$MNCs were counted as osteoclasts when more than 3 nuclei were present. Scale bar, $200 \mu \mathrm{m}$. (D) BMMs were infected by mock or FXR through a retrovirus packaging system. Infected BMMs were cultured with RANKL (100 ng/ml) and M-CSF (30 ng/ml) for 4 days. Scale bar, $200 \mu \mathrm{m}$. (E) Infected BMMs were cultured with M-CSF (30 ng/ml) in the presence or absence of RANKL (200 $\mathrm{ng} / \mathrm{ml}) \mathrm{for} 48$ h. Cell lysates were then subjected to western blot analysis with anti-NFATc1 antibody. (F-I) Histological bone sections from distal femur of $\mathrm{FXR}^{+/+}$and $\mathrm{FXR}^{-/}$mice were analyzed. N.Oc./BS (F), N.Mo. TRAP ${ }^{+}$cells/BS (G), N.Mu.Oc/BS (H) and Oc.S/BS (I). $n=6$ for each group. $(\mathbf{J}-\mathbf{K})$ Calvarias of $\mathrm{FXR}^{+/+}$and $\mathrm{FXR}^{-/}$mice that received the vehicle or LPS were subjected to TRAP staining. TRAP ${ }^{+}$stained area in calvaria was quantified using ImageJ. Representative images are shown in $(\mathrm{K}) . n=5$ for each group. Scale bar, $500 \mu \mathrm{m} .{ }^{*} p<0.05, * * p$ $<0.01$. N.Oc./BS: osteoclast number/bone surface; N.Mo.TRAP ${ }^{+}$cells/BS: number of TRAP ${ }^{+}$mononuclear cells/bone surface; N.Mu.Oc/ BS: number of multinuclear osteoclast/bone surface; Oc.S/BS: osteoclast surface/bone surface. 
stimulated NFATc1 induction and osteoclast formation [2-4]. Thus, we investigated whether pharmacological JNK inhibition by SP600125 or down-regulation of JNK by siRNA would closely mimic the genetic deletion of FXR. Since the basal level of JNK1/2 phosphorylation was maintained in $F X R^{-/-}$BMMs by RANKL (Figure 2D), we used a lower concentration $(0.3 \mu \mathrm{M})$ of SP600125 than is normally used $(1-10 \mu \mathrm{M})$. Interestingly, a low level of JNK $1 / 2$ inhibition led to a strong increase in osteoclastic differentiation by RANKL accompanied by a significant induction of NFATc1 (Figure 2G, 2H). Similar effects were seen by the use of siRNAs. The introduction of JNK-specific siRNA into $\mathrm{FXR}^{+/+}$BMMs showed a similar reduction in $\mathrm{JNK} 1 / 2 \mathrm{mRNA}$ expression similar to that in $F X R^{-1-}$ BMMs (Supplementary Figure 3). Compared to that with the control siRNA, the knock-down of JNK1/2 resulted in a significant increase in NFATc1 expression as well as in the formation of TRAP ${ }^{+}$MNCs by RANKL (Figure 2I, 2J). These results indicate that FXR has a negative role in osteoclast differentiation by modulating JNK signals downstream to RANKL.

\section{FXR deficiency up-regulates PPAR $\gamma$ and PGC- $1 \beta$ expression via the JNK pathway}

To gain insight into how FXR modulates osteoclast formation via $\mathrm{JNK}$, we investigated the expression of genes known to have a role in osteoclastogenesis. We found that JNK inhibitor $(0.3 \mu \mathrm{M})$ or JNK-specific siRNA enhanced the mRNA expression of peroxisome proliferator-activated receptor (PPAR) $\gamma$ and peroxisome proliferator-activated receptor-gamma coactivator 1 (PGC1) $\beta$ in BMMs (Figure $3 \mathrm{~A}, 3 \mathrm{~B}$ ). Furthermore, activation of FXR by CDCA decreased the mRNA expression of PPAR $\gamma$ and PGC-1 $\beta$, whereas inhibition of FXR by guggulsterone conversely resulted in an increase in these mRNA expressions (Figure 3C). Real-time PCR demonstrated that the mRNA expression of PPAR $\gamma$ and PGC- $1 \beta$ was significantly increased in $\mathrm{FXR}^{-/}$BMMs compared with that in $\mathrm{FXR}^{+/+} \mathrm{BMMs}$, which is consistent with these results (Figure 3D, 3E). Moreover, RANKL-induced mRNA expression levels of PPAR $\gamma$ and PGC-1 $\beta$ were maintained at significantly higher levels in $\mathrm{FXR}^{-/}$BMMs (Figure 3D, 3E). Similarly, the up-regulation of PPAR $\gamma$ protein expression in $\mathrm{FXR}^{-/}$BMMs was confirmed by western blot (Figure 3F).

PPAR $\gamma$ is a member of the nuclear hormone receptor superfamily of ligand-responsive transcription factors that can be activated by lipophilic ligands. PPAR $\gamma$ activation by rosiglitazone promotes hematopoietic stem cell (HSC) differentiation into osteoclasts, thus increasing bone resorption $[24,25]$. PGC-1 $\beta$ is a transcriptional coactivator that regulates energy metabolism by stimulating mitochondrial biogenesis and respiration of cells [26-29]. PGC- $1 \beta$ is required for the pro-osteoclastogenic and bone resorption-enhancing effects of PPAR $\gamma$ [24].
Since $F X R^{-/-}$BMMs have higher expression levels of PPAR $\gamma$ and PGC- $1 \beta$ compared to $\mathrm{FXR}^{+/+} \mathrm{BMMs}$, we investigated the effect of rosiglitazone, a PPAR $\gamma$ agonist, on RANKL-induced osteoclast differentiation from BMM cells. As previously reported [30], rosiglitazone increased osteoclast formation from $\mathrm{FXR}^{+/+} \mathrm{BMMs}$, and this induction was accelerated in $F X R^{-/-}$BMMs (Figure $3 \mathrm{G}$ ). We also revealed that the level of NFATCl was increased by rosiglitazone in $F X R+/+$ cells, but was significantly higher in $F X R^{-/-}$cells (Figure $3 \mathrm{H}$ ). These data suggest that up-regulation of PPAR $\gamma$ and PGC- $1 \beta$ expression by suppression of the JNK pathway leads to the increased osteoclast formation in $F X R^{-/-}$BMMs.

\section{FXR deficiency accelerates rosiglitazone-induced bone loss in vivo}

To further delineate the effect of increased PPAR $\gamma$ and PGC-1 $\beta$ expression in $F X R^{-/-}$BMMs on bone resorption and bone loss in vivo, we orally administrated $\mathrm{FXR}^{+/+}$or $F X R^{-/-}$mice with rosiglitazone or vehicle at $10 \mathrm{mg} / \mathrm{kg} / \mathrm{d}$ for 8 weeks. Femurs from the rosiglitazone group became darker in $F X R^{-/-}$mice than in $\mathrm{FXR}^{+/+}$mice (Figure 4A). The DXA analysis indicated that rosiglitazone-mediated reduction in BMD was significantly accelerated in the femurs of $F X R^{-/-}$mice (Figure 4B). A micro-CT analysis of the metaphyseal region of the femur showed that the trabecular bone volume per tissue volume (BV/TV) was significantly lower in $F X R^{-/-}$than $\mathrm{FXR}^{+/+}$mice following rosiglitazone treatment (Figure 4C). Consistently, two other bone parameters related to $\mathrm{BV} / \mathrm{TV}$ - trabecular thickness (Tb.Th) and trabecular number (Tb.N; linear density of trabecular bone) - were more significantly reduced in $\mathrm{FXR}^{-/-}$mice compared with $\mathrm{FXR}^{+/+}$mice by rosiglitazone treatment (Figure 4D, 4E). No obvious difference was seen in trabecular separation ( $\mathrm{Tb} . \mathrm{Sp}$ ) between rosiglitazonetreated $\mathrm{FXR}^{+/+}$and $F X R^{-/-}$mice (Figure 4F). Rosiglitazone treatment also resulted in a high structure model index (SMI) in $\mathrm{FXR}^{+/+}$mice, an indicator of increased fragility, which was more significantly increased in $F X R^{--}$mice (Figure 4G). Finally, two-dimensional visualization of the femoral area clearly showed that the massive loss of trabecular bone following rosiglitazone treatment was much higher in $\mathrm{FXR}^{-/-}$mice compared with $\mathrm{FXR}^{+/+}$mice (Figure 4H). These results indicate that FXR deficiency confers sensitivity to rosiglitazone-induced bone resorption and bone loss in vivo.

\section{FXR deficiency accelerates osteoclast formation via downregulation of IFN- $\beta$ signaling pathways}

To balance out osteoclastogenesis, RANKL also induces the $I F N-\beta$ gene in BMMs, and this induction constitutes a critical aspect of the negative feedback regulation of RANKL signaling that allows for the 
A

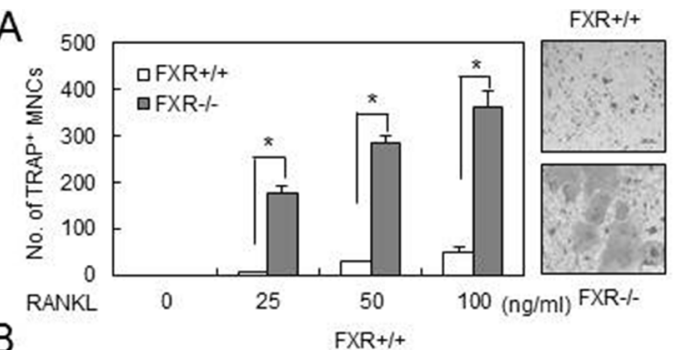

$\mathrm{B}$

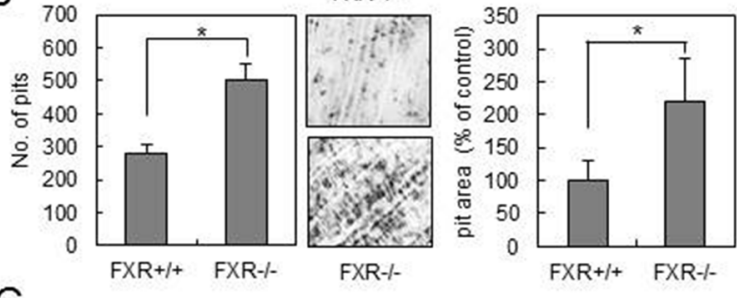

E

$\mathrm{F}$
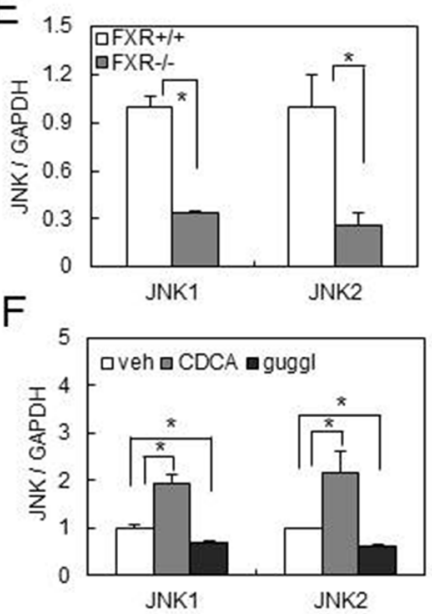

$\mathrm{H}$

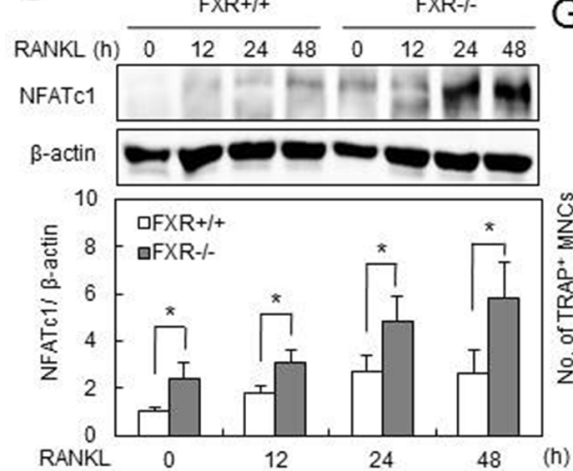

G
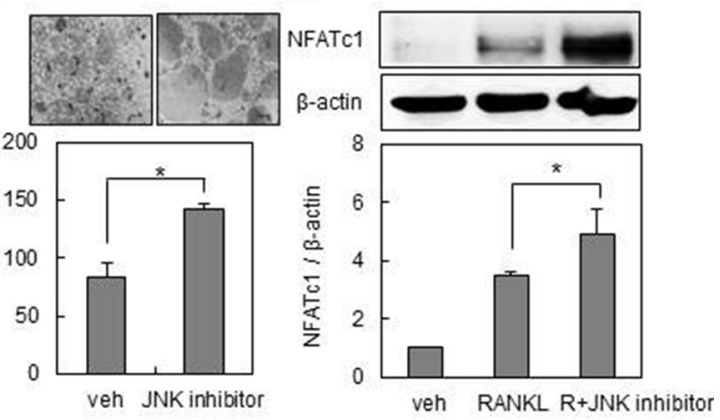

D
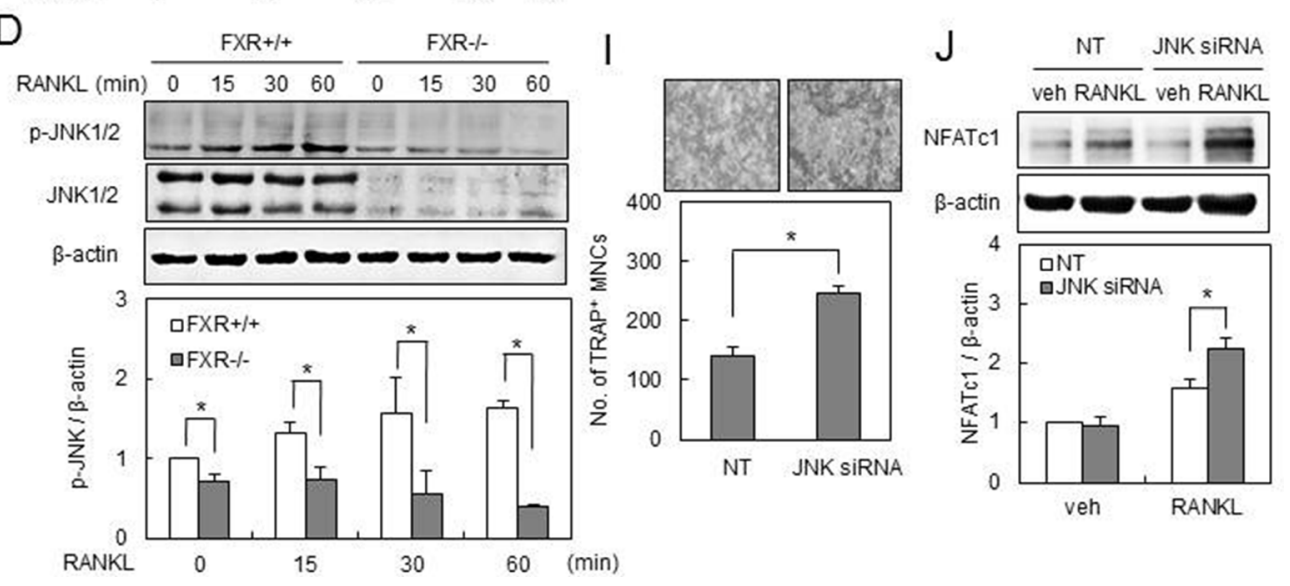

Figure 2: FXR deficiency increases osteoclast differentiation via downregulation of JNK1/2 expression. (A) BMMs from $\mathrm{FXR}^{+/+}$and $\mathrm{FXR}^{-/-}$mice were cultured with M-CSF and the indicated concentration of RANKL for 4 days, and TRAP ${ }^{+}$osteoclasts were counted. (B) BMMs from $\mathrm{FXR}^{+++}$and $\mathrm{FXR}^{-/}$mice were placed on dentine slices and cultured in the presence of RANKL (100 $\left.\mathrm{ng} / \mathrm{ml}\right)$ for 6 days. The remaining cells were removed and stained with toluidine blue. The images were observed under the microscope. The number of resorbed pits was counted and pit area in each dentine was quantified using ImageJ. (C) BMMs from $\mathrm{FXR}^{+/+}$and $\mathrm{FXR}^{-/}$mice were cultured with RANKL (200 ng/ml) for the indicated time. (D) BMMs from $\mathrm{FXR}^{+++}$and $\mathrm{FXR}^{-/}$mice were serum-starved for $16 \mathrm{~h}$ and stimulated with RANKL $(200 \mathrm{ng} / \mathrm{ml})$ for the indicated time. Cell lysates were then subjected to western blot analysis with anti-NFATc1, anti-p-JNK, or anti-JNK antibody. (E) The mRNA expression of JNK1 and JNK2 in $\mathrm{FXR}^{+++}$and $\mathrm{FXR}^{-/}$BMMs was analyzed by real-time PCR. (F) FXR ${ }^{+++}$ BMMs were cultured in the presence of $75 \mu \mathrm{M}$ CDCA or $0.3 \mu \mathrm{M}$ guggulsterone for $48 \mathrm{~h}$. The mRNA expression of JNK1 and JNK2 was analyzed by real-time PCR. (G) FXR ${ }^{+/+}$BMMs were cultured with RANKL $(100 \mathrm{ng} / \mathrm{ml})$ in the presence or absence of SP600125 $(0.3 \mu \mathrm{M})$, a JNK inhibitor, for 4 days. (H) FXR ${ }^{+/+}$BMMs were cultured with RANKL $(200 \mathrm{ng} / \mathrm{ml})$ in the presence or absence of SP600125 $(0.3 \mu \mathrm{M})$ for $48 \mathrm{~h}$. Cell lysates were then subjected to western blot analysis with anti-NFATc1 antibody. (I) FXR ${ }^{++/}$BMMs were transfected with 40 nM siRNA. The siRNA-transfected $\mathrm{FXR}^{+++}$BMMs were cultured with RANKL $(200 \mathrm{ng} / \mathrm{ml})$ for 3 days, and then TRAP ${ }^{+}$osteoclasts were counted. (J) The siRNA-transfected FXR ${ }^{+/+}$BMMs were cultured with RANKL ( $200 \mathrm{ng} / \mathrm{ml}$ ) for $48 \mathrm{~h}$. Cell lysates were then subjected to western blot analysis with anti-NFATc1 antibody. Data are expressed as means \pm SD from at least three independent experiments. Scale bar, $200 \mu \mathrm{m} .{ }^{*} p<0.05$. 

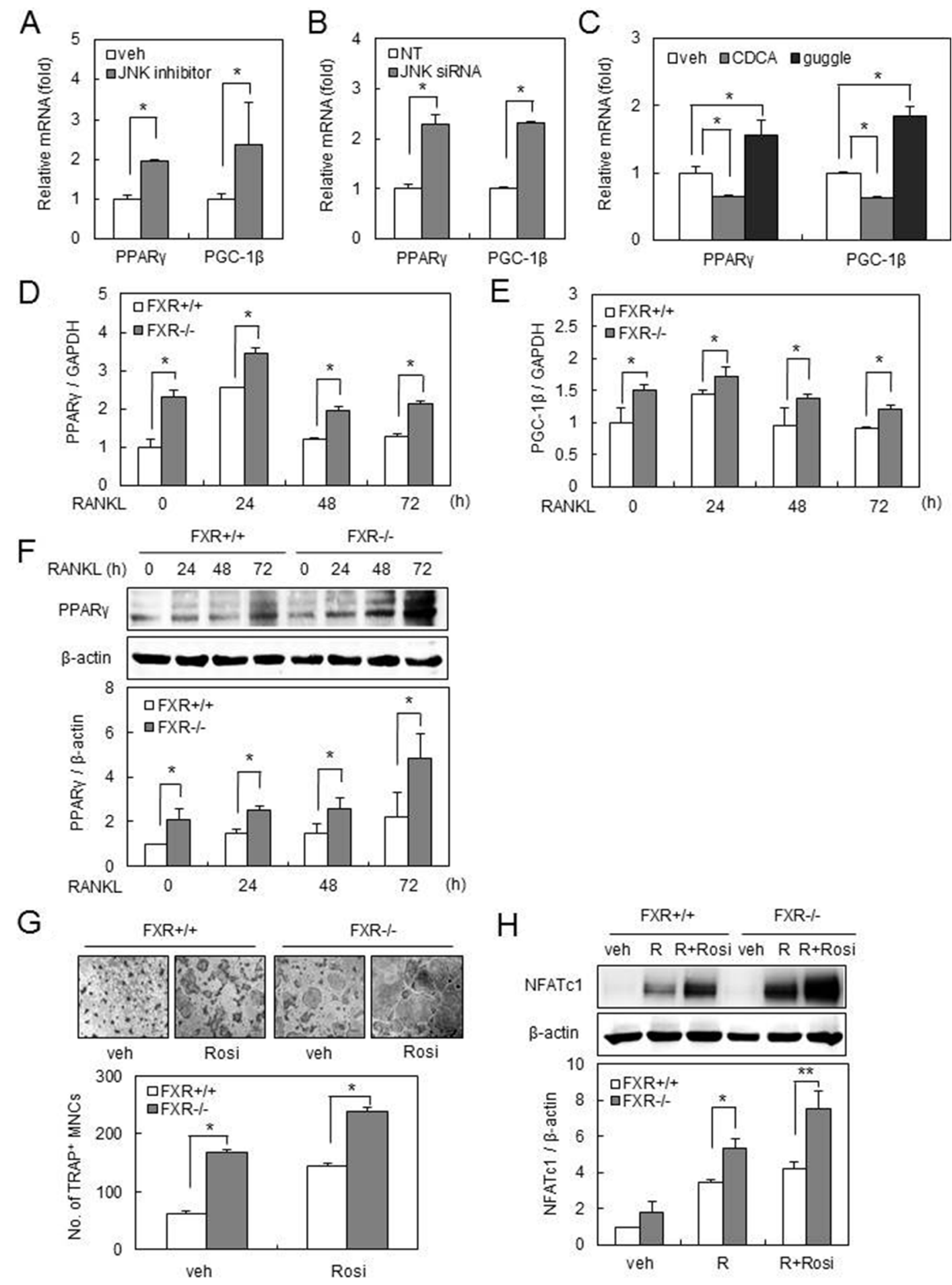

Figure 3: FXR deficiency up-regulates PPAR $\gamma$ and PGC-1 $\beta$ expression via downregulation of JNK. (A) FXR ${ }^{+/+} \mathrm{BMMs}$ were cultured in the presence or absence of SP600125 $(0.3 \mu \mathrm{M})$ for $24 \mathrm{~h}$. The mRNA expression of PPAR $\gamma$ or PGC-1 $\beta$ was analyzed by realtime PCR. (B) $\mathrm{FXR}^{++/}$BMMs were transfected with $40 \mathrm{nM}$ siRNA. The mRNA expression was analyzed by real-time PCR using PPAR $\gamma$ or PGC-1 $\beta$ primer. (C) $\mathrm{FXR}^{+/+}$BMMs were cultured with CDCA $(75 \mu \mathrm{M})$ or guggulsterone $(0.3 \mu \mathrm{M})$ for $24 \mathrm{~h}$. The mRNA expression of PPAR $\gamma$ or PGC- $1 \beta$ was analyzed by real-time PCR. (D-E) BMMs from $\mathrm{FXR}^{+++}$and $\mathrm{FXR}^{-/-}$mice were cultured with RANKL $(200 \mathrm{ng} / \mathrm{ml})$ for the indicated time. The mRNA level was analyzed by real-time PCR with PPAR $\gamma(\mathrm{D})$ or PGC-1 $\beta$ (E) primer. (F) FXR ${ }^{+/+}$and $\mathrm{FXR}^{-/}$ BMMs were cultured with RANKL $(200 \mathrm{ng} / \mathrm{ml})$ for the indicated time. Cell lysates were then subjected to western blot analysis with anti-PPAR $\gamma$ antibody. (G) $\mathrm{FXR}^{+/ /}$and $\mathrm{FXR}^{-/ /}$BMMs were cultured with RANKL $(100 \mathrm{ng} / \mathrm{ml})$ in the presence or absence of rosiglitazone $(0.3 \mu \mathrm{M})$ for 3 days. Scale bar, $200 \mu \mathrm{m}$. (H) BMMs from $\mathrm{FXR}^{+/+}$and $\mathrm{FXR}^{-/-}$mice were cultured with RANKL $(200 \mathrm{ng} / \mathrm{ml})$ in presence or absence of rosiglitazone $(0.3 \mu \mathrm{M})$ for $48 \mathrm{~h}$. Cell lysates were then subjected to western blot analysis with anti-NFATc1 antibody. Data are expressed as means $\pm \mathrm{SD}$ from at least three independent experiments. ${ }^{*} p<0.05,{ }^{* *} p<0.01$. 
suppression of excessive osteoclastogenesis [31]. Since FXR deficiency was shown to increase the pro-osteoclastogenic signals from RANKL, we next investigated whether FXR deficiency modulates the anti-osteoclastogenic mechanism of RANKL. RANKL increased mRNA expression of IFN- $\beta$ in $\mathrm{FXR}^{+/+}$BMMs, and this induction was significantly decreased in FXR-/BMMs (Figure 5A). The phosphorylation of STAT1 is known to be essential for IFN- $\beta$ signaling by RANKL [31]. The level of p-STAT1 by RANKL was increased in $F X R^{+/+}$BMMs, which was completely abrogated in $F X R^{-/-}$BMMs (Figure 5B). In accord with these findings,
A

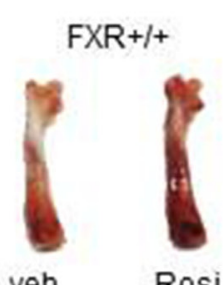

veh

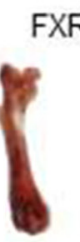

veh
$\mathrm{B}$

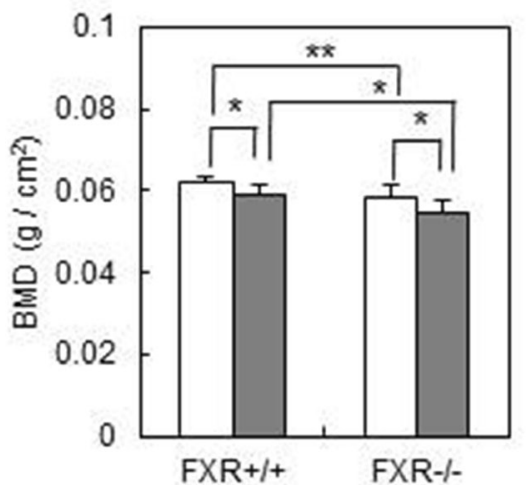

E

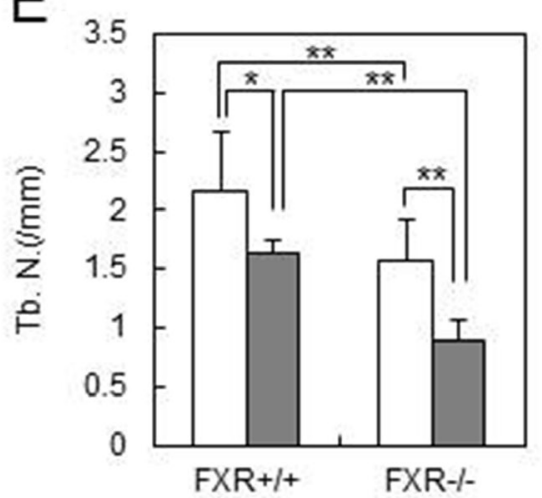

$\mathrm{H}$
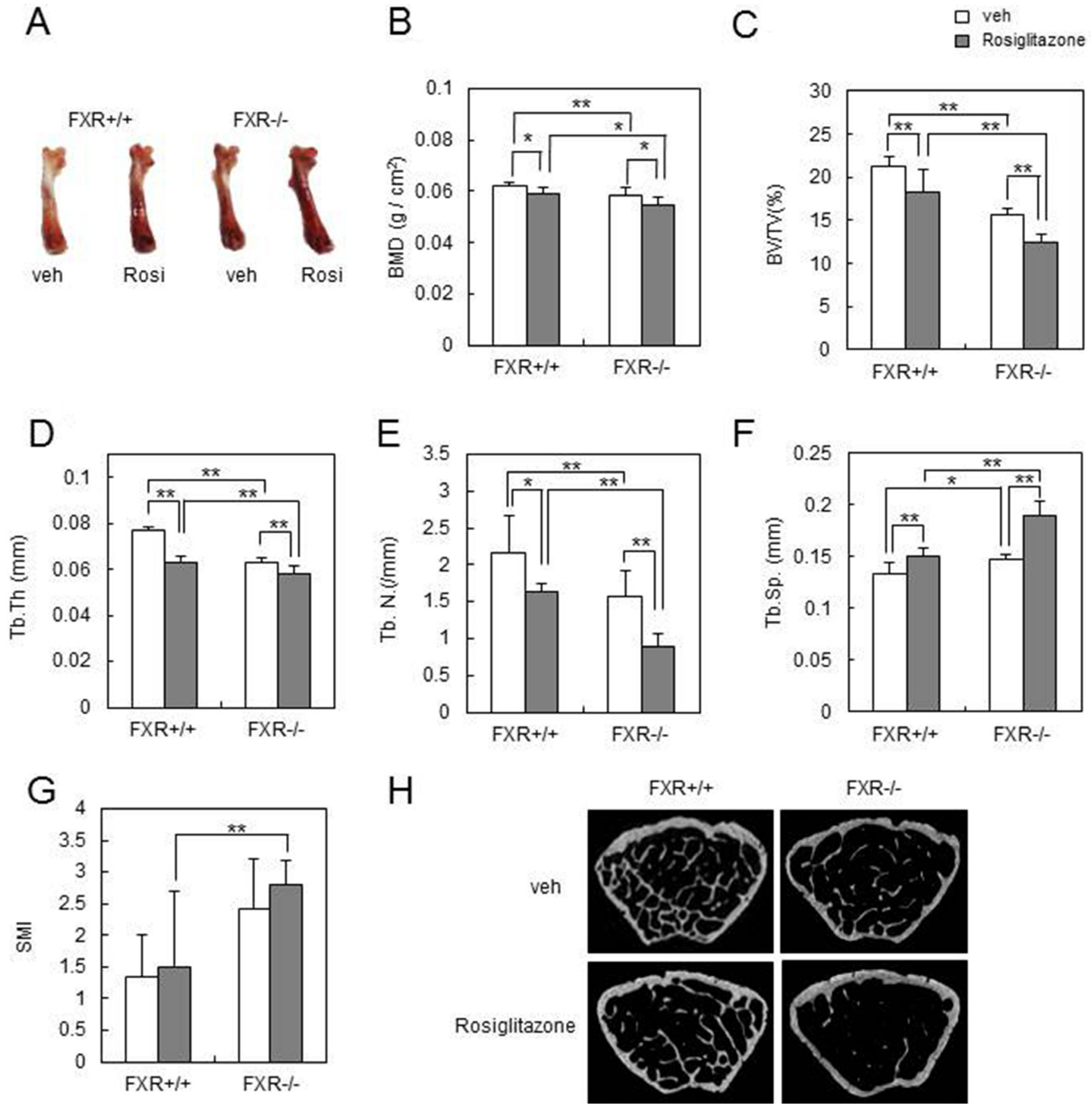

Figure 4: FXR deficiency increases rosiglitazone-induced bone loss in vivo. Male 12-week-old $\mathrm{FXR}^{+/+}$and $\mathrm{FXR}^{-/-}$mice were orally administered daily with rosiglitazone $\left(10 \mathrm{mg} / \mathrm{kg}\right.$ ) for 2 months, and mouse femurs were collected. (A) Femurs of FXR ${ }^{+/+}$or FXR FX $^{-/-}$ mice from each group. (B) BMD $\left(\mathrm{g} / \mathrm{cm}^{2}\right)$ of femurs from $\mathrm{FXR}^{+/+}$and $\mathrm{FXR}^{-/-}$mice was analyzed by DXA. (C-G) Various bone parameters were analyzed by micro-CT. BV/TV (\%) (C), Tb.Th (mm) (D), Tb.N (/mm) (E), Tb.Sp (mm) (F), SMI (G). (H) Two-dimensional micro-CT images of the distal metaphysis of the femurs. ${ }^{*} p<0.05, * * p<0.01$. BMD, bone mineral density; BV/TV, bone volume per tissue volume; Tb.Th, trabecular thickness; Tb.N, trabecular number; Tb.Sp, trabecular separation; SMI, structural model index. 
overexpression of FXR in BMMs increased the level of IFN- $\beta$ and $p-S T A T 1$ by RANKL when compared with the results with control vector (Figure 5C, 5D). The STAT family is located downstream of the JAKs [30]. We further demonstrated that RANKL increases JAK3 mRNA and protein levels in $\mathrm{FXR}^{+/+} \mathrm{BMMs}$, but not in $F X R^{-/-} \mathrm{BMMs}$ (Figure 5E, 5F).

Since the role of JAK3 in osteoclast formation has not been determined [32], we next assessed the effect of JAK3 downregulation on osteoclast differentiation. We found that a pharmacological JAK3 inhibitor accelerates RANKL-induced osteoclastogenesis in a dose-dependent manner (Figure 5G). Similar effects were seen in BMMs transfected with JAK3-specific siRNA (Figure 5H). In addition, compared with the control, knock-down of JAK3 in BMMs resulted in a significant decrease in the level of p-STAT1 (Figure 5I), followed by increased NFATc1 expression by RANKL (Figure 5J). These data suggest that the impairment of IFN- $\beta$ pathways via JAK3-STAT1 is another mechanism underlying the increased osteoclast formation in $\mathrm{FXR}^{-/-}$BMMs.

\section{FXR deficiency accelerates unloading- or OVX- induced bone loss in vivo}

We showed that FXR has an important role in OC differentiation and bone remodeling under physiological conditions. Next we used an unloading- or OVX-induced bone loss model in order to determine whether deletion of FXR affects bone loss under pathological conditions.

The effect of unloading was first investigated in FXR-deficient mice, using tail suspension as a model of hindlimb unloading [33]. $\mathrm{FXR}^{+/+}$and $\mathrm{FXR}^{-/-}$mice were subjected to tail suspension at age 8 weeks, and their skeletal response was analyzed 1 week later. Unloading induced a significantly greater femoral bone loss in $\mathrm{FXR}^{-/-}$ mice than in $\mathrm{FXR}^{+/+}$mice (Figure 6A). In agreement, BMD was significantly lower in $\mathrm{FXR}^{-/-}$mice than in $\mathrm{FXR}^{+/+}$mice after hindlimb unloading (Figure 6B). As FXR deficiency accelerates the unloading-induced reduction in BMD levels, we next examined the effects FXR deficiency on the microstructural bone deterioration that is induced by hindlimb unloading. Three dimensional micro-CT analyses revealed that the level of $\mathrm{BV} / \mathrm{TV}$ in the metaphyseal region of the femur was reduced by hindlimb unloading in $\mathrm{FXR}^{+/+}$mice, and FXR deficiency significantly increased the unloading-induced reduction in BV/TV (Figure 6C). Other bone parameters, including Tb.Th, Tb.N, Tb, Sp, and SMI, also confirmed more severe bone loss by hindlimb unloading in $F X R^{-/-}$mice compared to $\mathrm{FXR}^{+/+}$ mice (Figure 6D-6G). Furthermore, osteoclastogenesis was increased in bone marrow (Figure $6 \mathrm{H}$ ) or BMM cells (Figure 6I) from $\mathrm{FXR}^{-/-}$mice, in comparison to those from $\mathrm{FXR}^{+/+}$mice after tail-suspension. These data demonstrated that FXR deficiency accelerates unloadinginduced bone loss in vivo.
To further investigate the role of FXR in estrogen withdrawal-induced bone loss, we examined $\mathrm{FXR}^{+/+}$and $\mathrm{FXR}^{-1-}$ mice that were subjected to sham or OVX in vivo. Ten weeks after OVX, bone loss was even more severe in $\mathrm{FXR}^{-/-}$mice than in $\mathrm{FXR}^{+/+}$mice (Figure $7 \mathrm{~A}$ ). $\mathrm{FXR}^{-/-}$ mice showed lower BMD than $\mathrm{FXR}^{+/+}$mice (Figure $7 \mathrm{~B}$ ). In addition, OVX-induced structural bone alterations, including decreases in BV/TV, Tb.Th, Tb.N, and SMI, were heightened by lack of FXR (Figure 7C-7F). No significant difference was seen in Tb.Sp between $\mathrm{FXR}^{+/+}$ and $F X R-/-$ mice after OVX (Figure $7 \mathrm{G}$ ). These data demonstrated that FXR deficiency strengthened the OVXinduced bone loss in vivo. Taken together, out data suggest that FXR could be a pivotal modulator of bone loss in vivo under pathological conditions.

\section{DISCUSSION}

In this study, we suggest a novel role of FXR, a bile acid-sensing member of the nuclear receptor family, as a negative regulator of RANKL-induced osteoclast differentiation. We found that RANKL down-regulates FXR expression during osteoclast differentiation. Overexpression of FXR in BMMs attenuates RANKLinduced osteoclast differentiation by down-regulation of NFATc1, which is a key modulator for osteoclast differentiation. In agreement with this, $F X R^{-/-}$mice exhibited a significantly increased number of osteoclasts, which was partly attributed to a severe osteoporotic phenotype. In an attempt to elucidate the mechanisms by which FXR deficiency increases the osteoclastic differentiation, we demonstrated that the phosphorylation of JNK $1 / 2$ by RANKL as well as the expression of JNK1/2 were decreased in $F X R^{-/-} B M M s$. We found that the downregulation of $\mathrm{JNK}$ activity increased the expression of PPAR $\gamma$ and PGC-1 $\beta$, which might accelerate osteoclast formation in $F X R-/-$ BMMs.

The JNKs are members of the MAPK family and are activated by environmental stress [34]. The mammalian JNKs are encoded by three distinct genes (Jnk1, Jnk2, and Jnk3). JNK1 and JNK2 isoforms are ubiquitously expressed, whereas JNK3 is almost exclusively found in the brain, heart and testis [34]. Many previous studies have reported the role of JNK1/2 in osteoclast formation. In mouse BMMs, JNK activity is required during osteoclastogenesis to maintain the status of osteoclastic commitment [35]. A study using $J N K 1^{-1-}$ mice has also reported that activation of JNK1 is required for the efficient osteoclastogenesis of BMMs [36]. However, the present study is distinct from previous genetic and pharmacological studies that investigated the effects of a complete JNK blockade. In the present study, although FXR deficiency failed to effectively induce JNK phosphorylation by RANKL, the basal level of JNK phosphorylation was still maintained in BMMs. We speculate that the maintenance JNK phosphorylation at a 
A

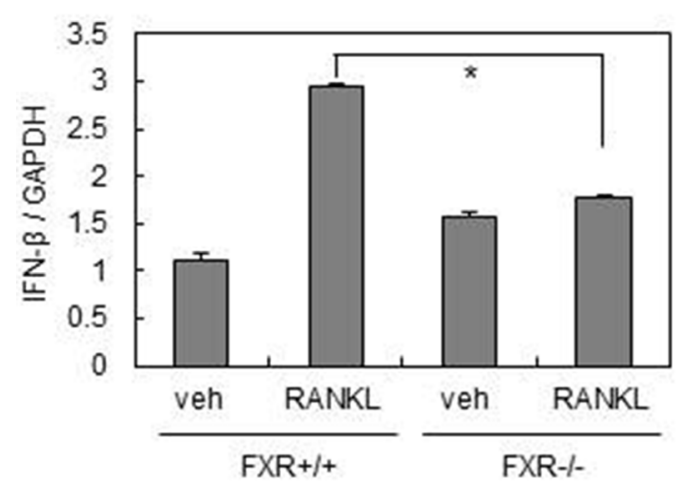

C
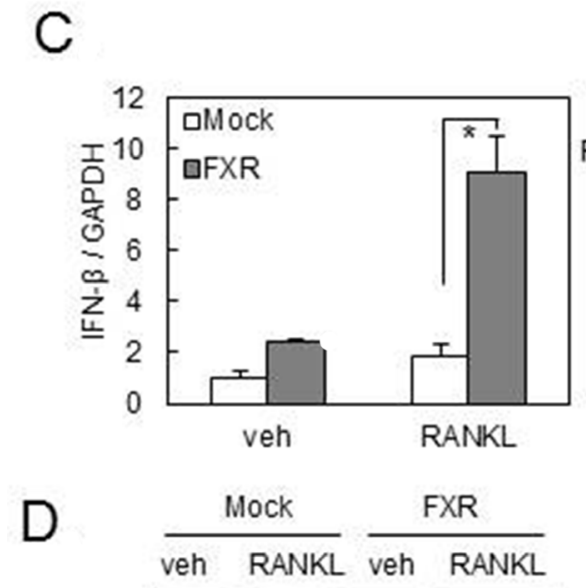

p-STAT1
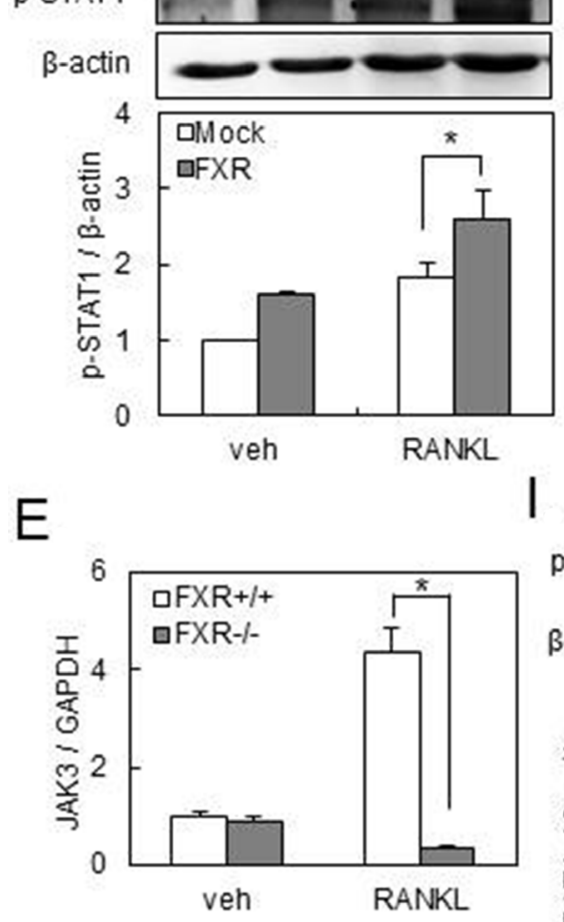

F

$G$
B

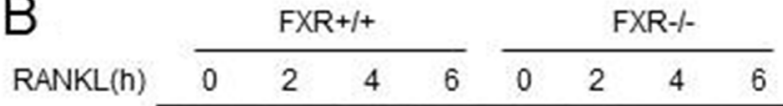

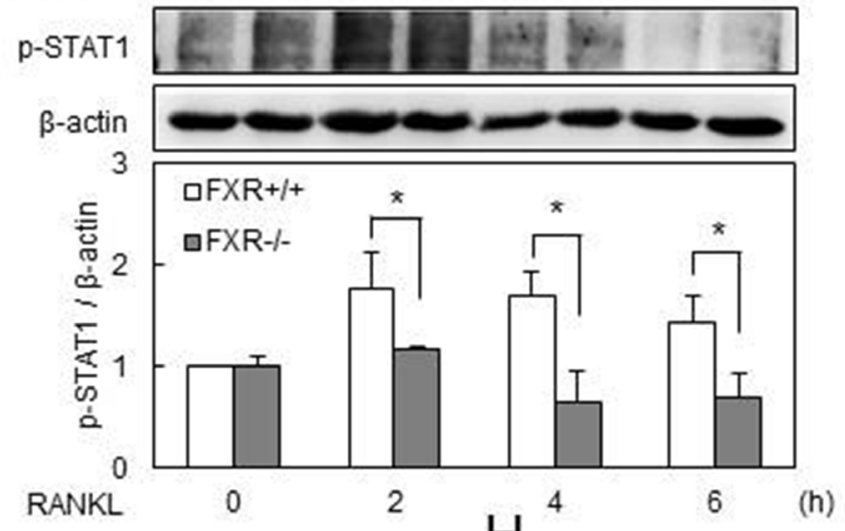

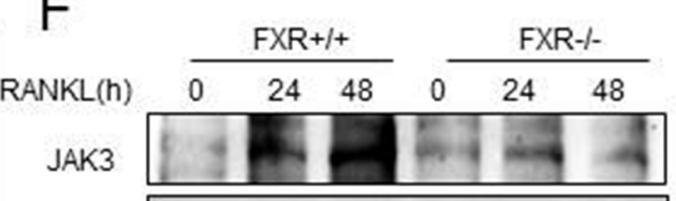
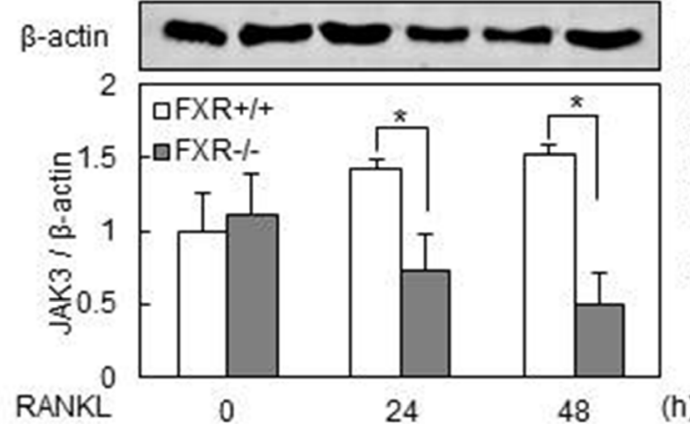

RANKL

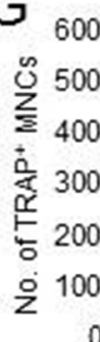

$\mathrm{H}^{4}$
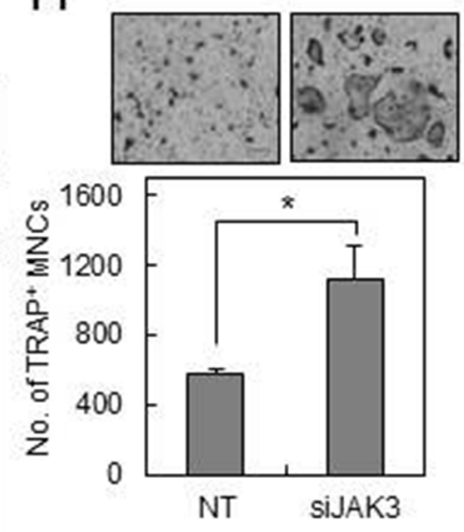

(h)

veh

JAK3 inhibitor

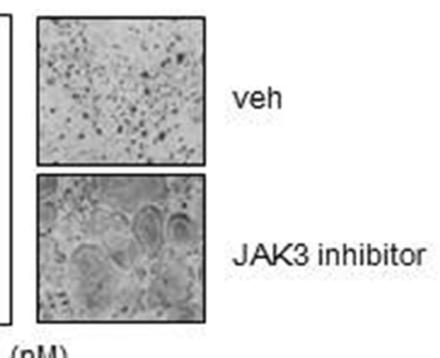

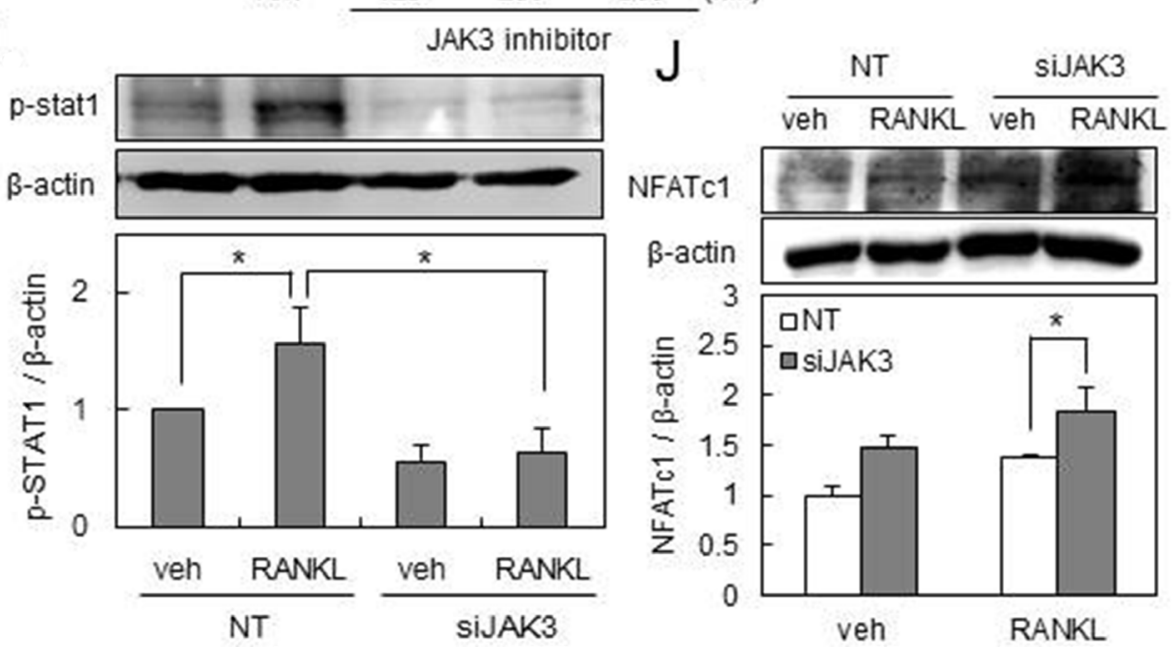


Figure 5: FXR deficiency down-regulates IFN- $\beta$ signaling pathways via JAK3-STAT1. (A, E) BMMs from FXR ${ }^{+/+}$and FXR $^{-/}$mice were cultured with RANKL $(200 \mathrm{ng} / \mathrm{ml})$ for $24 \mathrm{~h}$. The mRNA level was analyzed by real-time PCR with IFN- $\beta$ or JAK3 primer. (B) BMMs from $\mathrm{FXR}^{+/+}$and $\mathrm{FXR}^{-/-}$mice were serum-starved for $16 \mathrm{~h}$ and stimulated with RANKL (200 $\left.\mathrm{ng} / \mathrm{ml}\right)$ for the indicated time. (F) BMMs from $\mathrm{FXR}^{+++}$and $\mathrm{FXR}^{-/}$mice were cultured with RANKL $(200 \mathrm{ng} / \mathrm{ml})$ for the indicated time. Cell lysates were then subjected to western blot analysis with anti-p-STAT1 or anti-JAK3 antibody. (C, D) BMMs were infected by mock or FXR through a retrovirus packaging system. Infected BMMs were stimulated with RANKL ( $200 \mathrm{ng} / \mathrm{ml})$ for 4 or $24 \mathrm{~h}$. The mRNA levels of IFN- $\beta$ and p-STAT1 were analyzed by real-time PCR or western blotting. (G) BMMs from FXR ${ }^{+/+}$mice were cultured with RANKL (100 ng/ml) in the presence of tofacitinib, a JAK3 inhibitor, for 3 days. TRAP ${ }^{+}$MNCs were counted as osteoclasts when more than 3 nuclei were present. Scale bar, $200 \mu \mathrm{m}$. (H) $\mathrm{FXR}^{+/+}$BMMs were transfected with $40 \mathrm{nM}$ siRNA. The siRNA-transfected $\mathrm{FXR}^{+/+}$BMMs were cultured with RANKL $(200 \mathrm{ng} / \mathrm{ml})$ for 3 days, and then $\mathrm{TRAP}^{+}$osteoclasts were counted. (I) The siRNA-transfected $\mathrm{FXR}^{+/+} \mathrm{BMMs}$ were serum-starved for $16 \mathrm{~h}$ and stimulated with RANKL (200 ng/ml) for 4 h. (J) The siRNA-transfected FXR ${ }^{+/+}$BMMs were cultured with RANKL (200 ng/ml) for $24 \mathrm{~h}$. Cell lysates were then subjected to western blotting analysis with anti-p-STAT1 or anti-NFATc1 antibody. Data are expressed as mean \pm SD from at least three independent experiments. Scale bar, $200 \mu \mathrm{m} .{ }^{*} p<0.05$.

basal level permits the acceleration of osteoclastogenesis by increased PPAR $\gamma$-PGC- $1 \beta$ expression.

There is much evidence to show that the nuclear receptor PPAR $\gamma$ regulates skeletal homeostasis through its direct effect on osteoclasts $[25,30,37,38]$. Genetically, the loss of PPAR $\gamma$ function in mouse hematopoietic lineages causes osteoclast defects, which present as osteopetrosis [25]. Pharmacologically, rosiglitazone-induced PPAR $\gamma$ activation causes bone loss in mice by enhancing osteoclastogenesis and bone resorption in vivo [25]. PPAR $\gamma$ modulates transcription through the ligand-mediated recruitment of coactivators [39]. PGC-1 $\beta$ (also known as Ppargc1 $\beta$ ) is a transcriptional coactivator and is strongly induced by RANKL and rosiglitazone during osteoclast differentiation $[37,39]$. Knockdown of PGC-1 $\beta$ in vitro inhibits osteoclast differentiation, and global PGC- $1 \beta$ deletion in mice results in increased bone mass due to defects in osteoclasts [40]. Furthermore, targeted deletion of PGC- $1 \beta$ in the osteoclast lineage resulted in complete resistance to rosiglitazoneinduced bone loss in vivo and severe attenuation of rosiglitazone-stimulated osteoclastogenesis ex vivo [39]. In accord with these studies, we suggested that the upregulation of PPAR $\gamma$ and PGC- $1 \beta$ in $\mathrm{FXR}^{-/}$BMMs might lead to increased osteoclast formation and bone resorption in vitro and in vivo. We further demonstrated that the increased expressions of PPAR $\gamma$ and PGC-1 $\beta$ were caused by the reduction of JNK1/2 in $\mathrm{FXR}^{-/}$BMMs. Indeed, a previous report demonstrated that PPAR $\gamma$ mRNA levels were increased in JNK1/2-deficient cells, using microarray analysis [41], confirming our present results. To our knowledge, the present study is the first to demonstrate JNK-mediated negative regulation of osteoclastogenesis via PPAR $\gamma$ and PGC- $1 \beta$.

It has been reported that IFN- $\beta$ limits the excessive activation of osteoclast differentiation upon RANKL stimulation in a feedback-regulated manner [31]. In fact, IFN- $\beta$-knock-out mice exhibited an osteoporotic phenotype due to augmented osteoclastogenesis, indicating that IFN- $\beta$ plays a critical role in the negative regulation of osteoclastogenesis for bone homeostasis [42]. Furthermore, STAT1 has been suggested as a mediator of IFN- $\beta$ during osteoclastogenesis because STAT1-deficient BMMs are resistant to the suppression of osteoclast differentiation by IFN- $\beta$ [31, 42]. In this study, it was demonstrated that FXR deficiency impaired the negative regulation of IFN- $\beta$ signaling in osteoclastogenesis. We also found that FXR acts through JAK3 to modulate IFN- $\beta$ signaling, since the lack of induction of JAK3 in $\mathrm{FXR}^{--}$BMMs correlated with the resistance to the negative regulatory effects of IFN- $\beta$ on osteoclastogenesis. These data provide new insights into the role of JAK3 in RANKL-induced osteoclast formation. Taken together, FXR is important to maintain homeostatic osteoclast differentiation through negative regulation of the PPAR $\gamma$ and PGC- $1 \beta$ pathways and positive regulation of the IFN- $\beta$ and STAT1 pathways.

In addition to the role of FXR in physiological conditions, we also found that FXR modulates osteoclastogenesis and bone loss in pathological conditions caused by unloading or estrogen withdrawal. The world population is aging and the proportion of individuals over 65 is increasing [43]. Considering that menopause occurs around the age of 50, millions of women will live many years at risk for osteoporosis and fractures. Furthermore, in a super-aged society, unloading-induced osteoporosis is also a critical issue in bedridden patients with reduced locomotor function. Thus, an understanding of the molecular mechanisms of menopause- and unloadinginduced osteoporosis is required. In this study, our data demonstrated that FXR has potential as a novel drug target for preventing postmenopausal osteoporosis and unloading-induced bone loss.

In summary, we have proposed a new regulatory role of FXR in osteoclastogenesis (Figure 7H) in physiological and pathological bone loss associated with postmenopausal osteoporosis and disuse-induced bone loss. Identification and elucidation of key mediators of RANKL should aid in the development of therapeutic strategies for the treatment of such skeletal diseases.

\section{MATERIALS AND METHODS}

\section{Reagents}

Guggulsterone, SP600125, and rosiglitazone were purchased from Cayman Chemical Company (Ann Arbor, MI, USA). Tofacitinib (JAK3 inhibitor) was purchased from LC Laboratories (Woburn, MA, USA). Antibodies against $\mathrm{p}-\mathrm{JNK}$ and JNK were purchased from Cell 
Signaling Technology (Beverly, MA, USA). Antibodies against NFATc1 and JAK3 were purchased from Santa Cruz (Santa Cruz, CA, USA). Recombinant murine M-CSF and RANKL were purchased from Peprotech (Rocky Hill, NJ, USA). All other reagents were purchased from Sigma-Aldrich (St. Louis, MO, USA).

A
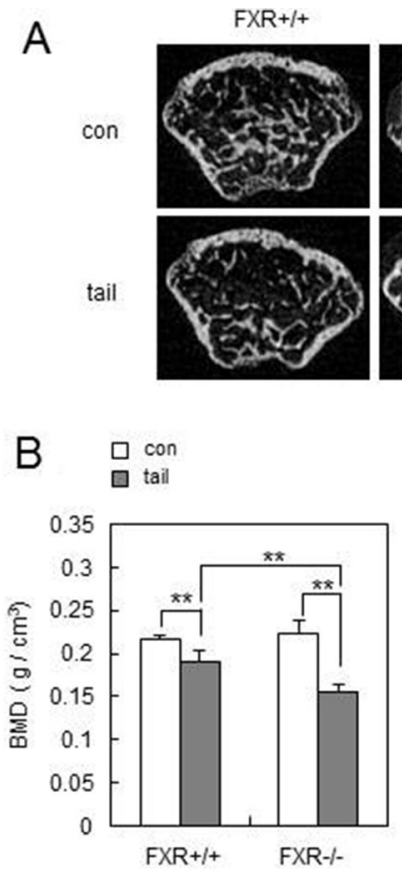

$E$
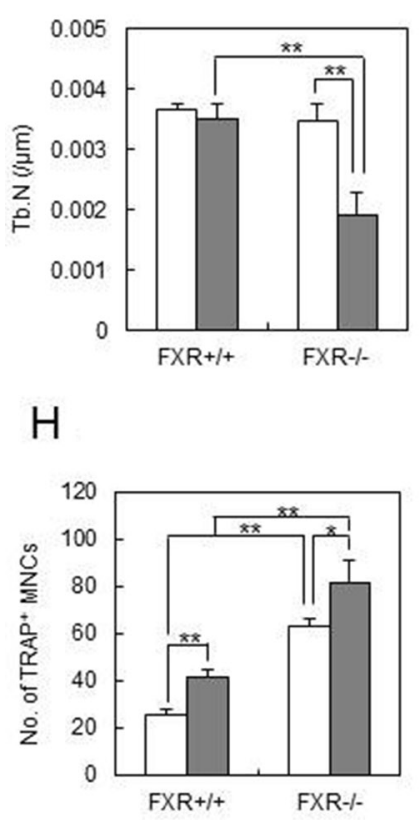

C

\section{Animal model}

$\mathrm{FXR}^{-/}$mice were generously provided by $\mathrm{F}$. Gonzalez (NIH, Bethesda, Maryland, USA) and backcrossed to a C57BL/6J background for 10 generations. Genotyping of the mice was performed

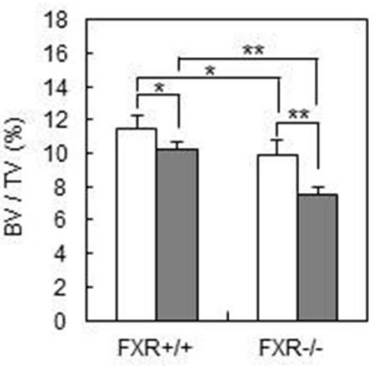

$\mathrm{F}$
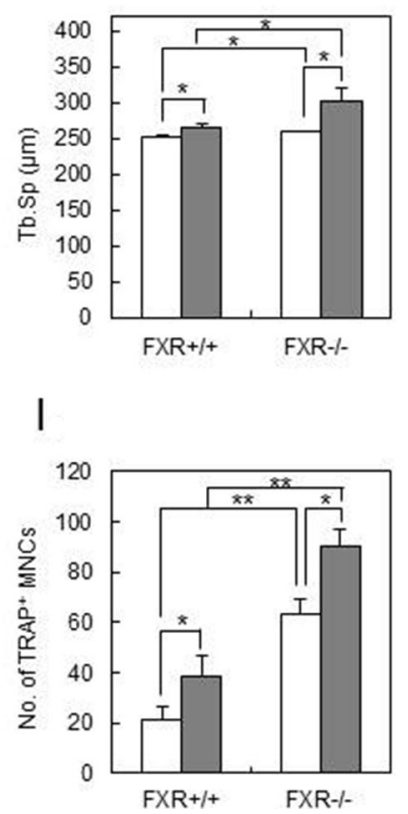

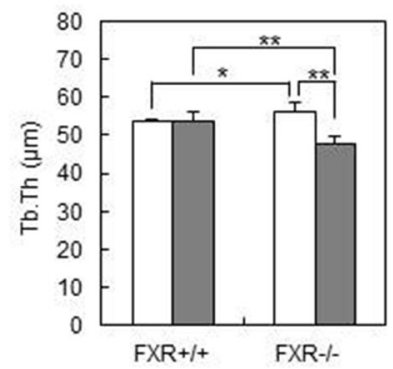

G
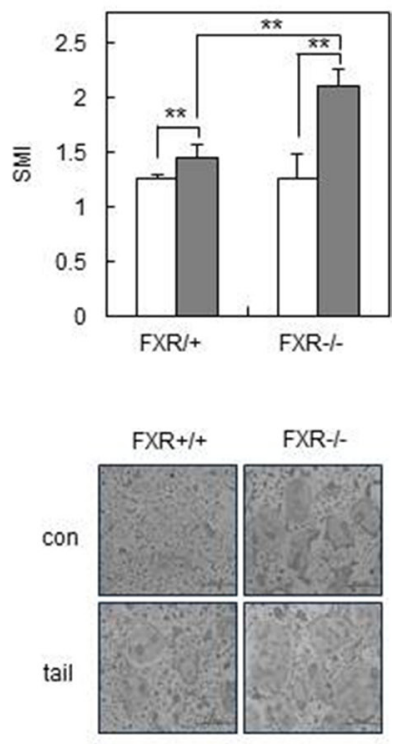

Figure 6: FXR deficiency accelerates unloading-induced bone loss in vivo. Male 8-week-old $\mathrm{FXR}^{+/+}$and $\mathrm{FXR}^{-/-}$mice were subjected to tail suspension, and mouse femurs were collected after 1 week. (A) Two-dimensional micro-CT images of the distal metaphysis of the femurs. (B-G) Various bone parameters of femurs were analyzed by micro-CT. BMD $\left(\mathrm{g} / \mathrm{cm}^{3}\right)(\mathrm{B}), \mathrm{BV} / \mathrm{TV}(\%)(\mathrm{C}), \mathrm{Tb} . \mathrm{Th}(\mu \mathrm{m})(\mathrm{D})$, Tb.N $(/ \mu \mathrm{m})(\mathrm{E}), \mathrm{Tb} . \mathrm{Sp}(\mu \mathrm{m})(\mathrm{F}), \mathrm{SMI}(\mathrm{G}) .(\mathrm{H}-\mathrm{I})$ bone marrow cells $(\mathrm{H})$ or BMMs (I) from $\mathrm{FXR}^{+/+}$and $\mathrm{FXR}^{-/}$mice were cultured with RANKL (100 ng/ml) and M-CSF (30 ng/ml) for 4 days and then TRAP ${ }^{+}$osteoclasts were counted. ${ }^{*} p<0.05,{ }^{* *} p<0.01$. 


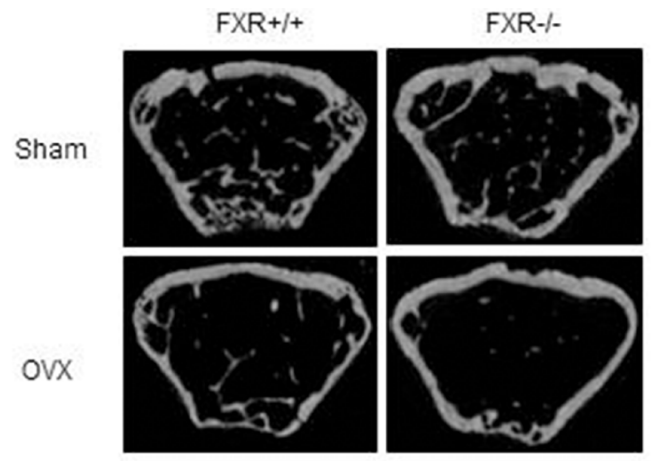

B
$\square$ sham
ㅁ ovx
C
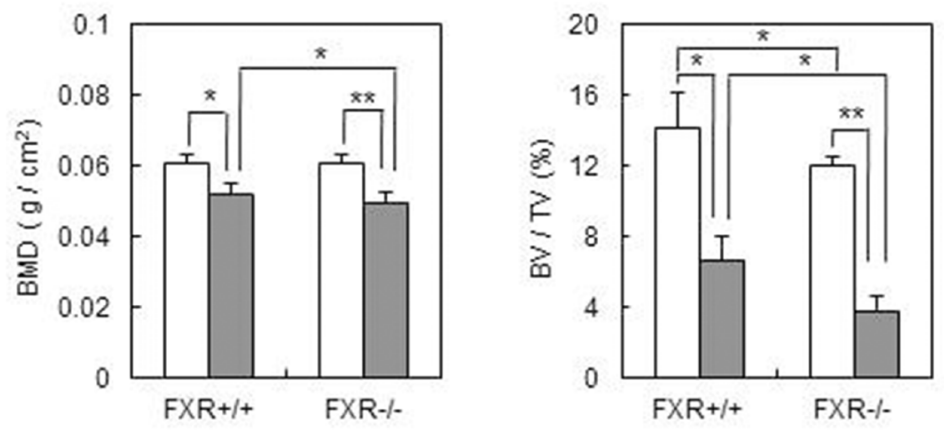

E

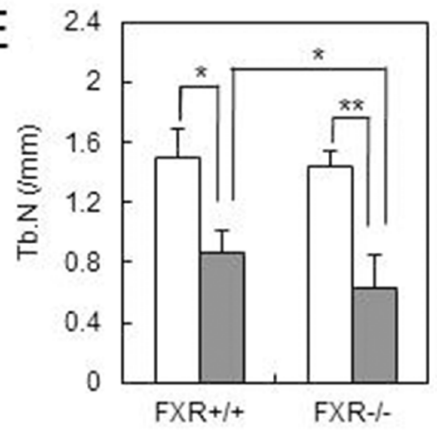

$\mathrm{H}$

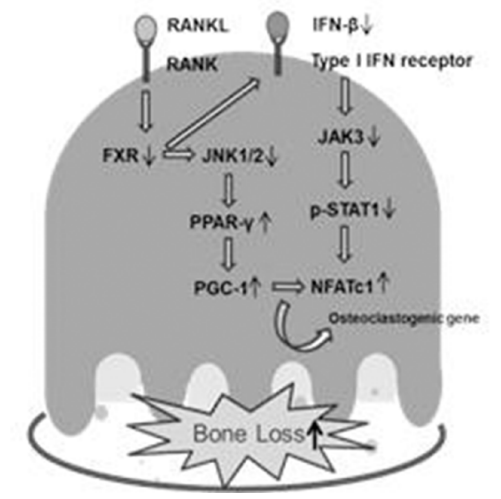

F

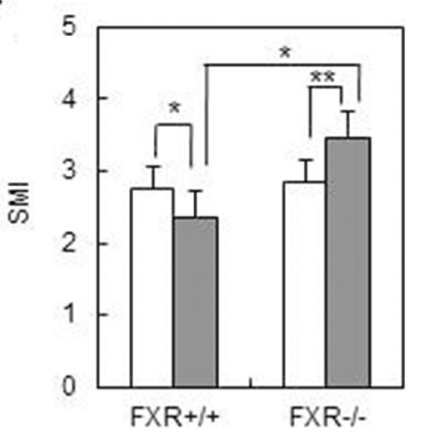

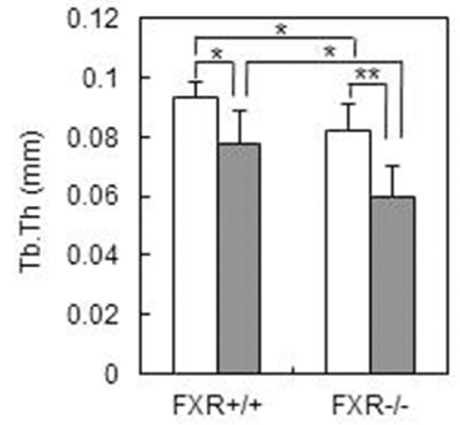

D

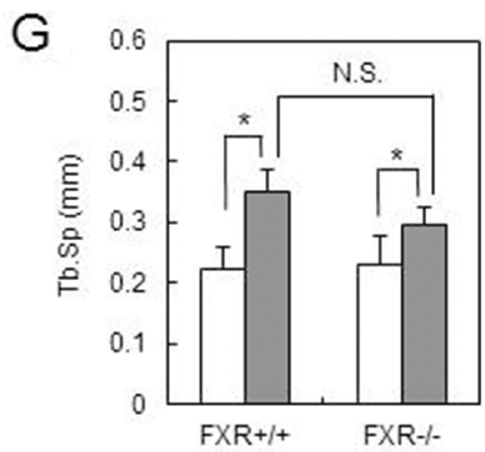

Figure 7: FXR deficiency accelerates OVX-induced bone loss in vivo. Female 12-week-old mice underwent either OVX or sham operation, and mouse femurs were collected after 10 weeks. (A) Two-dimensional micro-CT images of the distal metaphysis of the femurs. (B) BMD $\left(\mathrm{g} / \mathrm{cm}^{2}\right)$ of femur from $\mathrm{FXR}^{+/+}$and $\mathrm{FXR}^{-/-}$mice was analyzed by DXA. (C-G) Various bone parameters of femurs were analyzed by micro-CT. BV/TV (\%) (C), Tb.Th (mm) (D), Tb.N (/mm) (E), SMI (F), Tb.Sp (mm) (G). (I) A simplified model for the role of FXR in osteoclastogenesis. $* p<0.05, * * p<0.01$. N.S.: Not Significant. 
as previously described [22]. Mouse littermates with a genotype of C57BL/6J WT (FXR+/+) were used as controls. All mice were maintained in the animal facility of the Sookmyung Women's University on a 12:12-h lightdark cycle, and were allowed food and water ad libitum. All experiments were performed in accordance with the institutional guidelines approved by the Sookmyung Women's University Animal Care and Use Committee.

\section{Cells and culture system}

Mouse bone marrow cells were isolated from 10-12-week-old $\mathrm{FXR}^{+/+}$or $\mathrm{FXR}^{-/-} \mathrm{C} 57 \mathrm{BL} / 6 \mathrm{~J}$ background mice. Bone marrow cells were cultured in complete $\alpha$-MEM containing 10\% (v/v) fetal bovine serum (FBS), supplemented with $5 \mathrm{ng} / \mathrm{ml}$ recombinant murine M-CSF (PeproTech) for $12 \mathrm{~h}$ to separate adherent and nonadherent cells. The non-adherent cells were then harvested and cultured with $30 \mathrm{ng} / \mathrm{ml}$ M-CSF. After 4 days of culturing, the floating cells were removed and the attached cells were used as BMMs. All cells were cultured in $\alpha$-MEM containing $5 \%(\mathrm{v} / \mathrm{v}) \mathrm{FBS}$ at $37^{\circ} \mathrm{C}$ in a humidified atmosphere in $5 \% \mathrm{CO}_{2}$ conditions.

\section{TRAP staining of osteoclasts}

Osteoclasts were observed by staining for TRAP activity. Cultured cells were fixed with $10 \%$ formalin for $10 \mathrm{~min}$, permeabilized with ethanol:acetone $(50: 50 \mathrm{v} / \mathrm{v})$ for $1 \mathrm{~min}$ at room temperature, and incubated in acetate buffer (pH 5.2) containing naphthol ASMX phosphate (Sigma-Aldrich) as the substrate and Fast Red Violet LB salt (Sigma-Aldrich) as the dye for the reaction product in the presence of $50 \mathrm{mM}$ sodium tartrate. After washing with distilled water and drying, $\mathrm{TRAP}^{+} \mathrm{MNCs}(n>3)$ were counted using a light microscope.

\section{Quantitative real-time PCR}

Total RNA was purified with easy-BLUE (iNtRON Biotechnology, Seoul, Korea), and cDNA was prepared from $5 \mu \mathrm{g}$ of RNA using Revert Aid ${ }^{\text {TM }}$ First-Strand cDNA Synthesis Kit (Fermentas, Glen Burnie, MD, USA). Primers for osteoclastogenic genes used in this study are shown in Supplementary Table 1. Real-time PCR reactions were performed in a total volume of $20 \mu \mathrm{l}$, using SYBR ${ }^{\circledR}$ Green PCR Master Mix (Applied Biosystems, Foster City, CA, USA) according to the manufacturer's protocol. Thermocycling was performed using a 7500 real-time PCR System (Applied Biosystems) with the following conditions: initial hold at $95^{\circ} \mathrm{C}$ for $10 \mathrm{~min}$, followed by 40 cycles of denaturation at $95^{\circ} \mathrm{C}$ for $15 \mathrm{~s}$, annealing at $58^{\circ} \mathrm{C}$, and extension at $60^{\circ} \mathrm{C}$ for $1 \mathrm{~min}$. Data were analyzed using 7500 System Sequence Detection Software version 2.0 (Applied Biosystems). An index mRNA level was assessed using a threshold cycle $(\mathrm{Ct})$ value and normalized against glyceraldehyde 3-phosphate dehydrogenase (GAPDH) expression.

\section{Immunoblot analysis}

Cells were lysed in lysis buffer (50 mM Tris $\mathrm{HCl}, \mathrm{pH}$ 7.5, $150 \mathrm{mM} \mathrm{NaCl}, 1 \% \mathrm{NP}-40,1 \mathrm{mM}$ EDTA, 0.25\% SDS, $1 \mathrm{mM}$ NaF, $1 \mathrm{mM} \mathrm{Na3VO} 4,1 \mathrm{mM}$ phenylmethylsulfonyl fluoride, pepstatin, leupeptin, and aprotinin) and were clarified by centrifugation. Protein was measured by Bradford assay (Bio-Rad Laboratories, Inc., Benicia, CA, USA), and equal amounts of protein were separated by sodium dodecyl sulfate-polyacrylamide gel electrophoresis (SDS-PAGE) and transferred onto a polyvinylidene fluoride (PVDF) membrane (Immobilon-P; Millipore, Bedford, MA, USA). The membranes were blocked with $5 \%$ nonfat-milk in phosphate-buffered saline with $0.1 \%$ Tween 20 (PBS-T) and then immunostained with the indicated antibodies. The membranes were developed using an enhanced chemiluminescence detection kit (Amersham Biosciences, Buckinghamshire, United Kingdom).

\section{Bone resorption assay}

BMMs were differentiated on dentin slices with M-CSF and RANKL (PeproTech, Inc., Rocky Hill, NJ, USA) for 8 days. The cells were removed from the dentin slice by wiping the its surface, and then the slices were stained with toluidine blue $(1 \mu \mathrm{g} / \mathrm{ml}$; J.T. Baker, Philipsburg, NJ, USA). The number of pits formed by bone resorption on the dentin slices was counted. Image analysis was accomplished using ImageJ software (version 1.32; National Institute of Health, Bethesda, MD, USA) according to the manufacturer's protocol.

\section{Retroviral gene transduction}

To generate retroviral stocks, pMX-IRES-FXR was transfected into the packaging cell line Platinum-E (Plat-E. kindly provided by Prof. S. Y. Lee at Ewha University). Viral supernatant was collected from culture media at 48 $\mathrm{h}$ after transfection using Lipofectamine 2000 (Invitrogen, Carlsbad, CA, USA) according to the manufacturer's instructions. For infection with retroviruses, BMMs were incubated with the viral supernatant ( $4 \mathrm{ml} / \mathrm{dish})$, polybrene (10 $\mu \mathrm{g} / \mathrm{ml}$, Santa Cruz, CA, USA), and M-CSF (30 ng/ml) for 2 days, and selected by puromycin $(2 \mu \mathrm{g} / \mathrm{ml}$; SigmaAldrich, St. Louis, MO, USA) for an additional $48 \mathrm{~h}$.

\section{siRNA transfection}

BMMs were seeded into 48-well plates at a density of $3.5 \times 10^{4}$ cells/well with $30 \mathrm{ng} / \mathrm{ml}$ M-CSF. After $24 \mathrm{~h}$, cells were transfected with 40 $\mathrm{nM}$ mouse JNK on-target plus smart pool siRNAs (5'-AAAGAATGTCCTACCTTCT-3')

(QIAGEN, 
Hilden, Germany) or mouse JAK3 on-target plus smart pool siRNAs (5'-CACGTTAGACTTTGCCATCCA-3'; QIAGEN) using Lipofectamine 2000 (Invitrogen, Carlsbad, CA, USA) according to the manufacturer's instructions. The control contained $40 \mathrm{nM}$ non-targeting siRNA (QIAGEN). The transfection took place in $2.5 \mathrm{ml}$ of serum-free medium for $6 \mathrm{~h}$; the cells were then cultured for 4 days in complete media containing $30 \mathrm{ng} / \mathrm{ml} \mathrm{M-CSF}$ and $100 \mathrm{ng} / \mathrm{ml}$ RANKL for osteoclast formation.

\section{LPS-induced osteoclast formation in vivo}

To investigate the contribution of FXR to LPSinduced osteoclast formation in vivo, 12-week-old $\mathrm{FXR}^{+/+}$ and FXR $-/-$ male mice were directly injected with 0.5 $\mathrm{mg} / \mathrm{mouse}$ LPS on calvarial bone ( $n=5$ per each group). After 6 days, mice were euthanized. Whole calvaria were fixed in $4 \%$ paraformaldehyde for $24 \mathrm{~h}$ and then stained with TRAP. Image analysis was accomplished using ImageJ software (version 1.32; National Institute of Health, Bethesda, MD, USA) according to the manufacturer's protocol.

\section{Rosiglitazone-induced bone loss in vivo}

12-week-old male $\mathrm{FXR}^{+/+}$and $\mathrm{FXR}^{-/-}$mice were orally administered daily either with rosiglitazone (10 $\mathrm{mg} / \mathrm{kg}$; Cayman Chemical Company, Ann Arbor, MI, USA) or with control ( $n=10$ per each group). The mice were euthanized 2 months after administration. Femurs of mice were fixed with $70 \%$ ethanol at $4{ }^{\circ} \mathrm{C}$ until analysis. Bone mineral density $\left(\mathrm{BMD} ; \mathrm{g} / \mathrm{cm}^{2}\right)$ of femurs was measured and analyzed by the dual energy X-ray absorptiometry (DXA) instrument PIXIMUS (GE Lunar, Madison, WI, USA). Three-dimensional measurements were performed with a micro-CT scanner and associated analysis software (Model 1172; Skyscan, Antwerp, Belgium) at 9-mm voxel size. Image acquisition was performed at $35 \mathrm{kV}$ of energy and at an intensity of 220 $\mathrm{mA}$. The threshold was set to segment the bone from the background, and the same threshold setting was used for all samples.

\section{Tail suspension model}

Tail suspension was conducted by applying a tape to the surface of the hindlimb to set a metal clip [23]. The other end of the clip was fixed to an overhead bar. The height of the bar was adjusted to maintain the mice at a 30 degrees head-down tilt with the hindlimbs elevated above the floor of the cage. Male 8-week-old FXR ${ }^{+/+}$and $\mathrm{FXR}^{-/-}$ mice were subjected to tail suspension for 7 days. Loaded control mice were also housed under the same conditions (except for tail suspension) and for the same duration ( $n=7$ per group).

\section{OVX-induced bone loss in vivo}

Female 12-week-old $\mathrm{FXR}^{+/+}$and $\mathrm{FXR}^{-/-}$mice underwent either ovariectomy (OVX) or sham operation ( $n=14$ per group). The mice were euthanized after 10 weeks. Femurs of mice were fixed with $70 \%$ ethanol at $4^{\circ} \mathrm{C}$ and were analyzed by DXA and micro-CT as mentioned above.

\section{Statistical analysis}

The descriptive statistics present data as the mean \pm SD. Means were compared by Student's $t$-test (for comparison of two means) or ANOVA (for multiple comparisons) with a least significant difference post hoc test. Data represent the means and the SD from at least three independent experiments. Data were reported as statistically significant when the $p$-value $<0.05$ for comparisons. Calculations were performed with the software package SPSS (Ver. 21.0 for windows; SPSS, Inc., Chicago, IL, USA).

\section{Author contributions}

T.Z. and J.H.K. carried out the breeding of mice and analysis of gene expression. T.Z., J.H.K. and J.S.S. performed in vitro and in vivo studies. J.W.K., J.T.K., C.S.S. and H.L contributed to in vivo data analysis. M.Y. designed the experiments and wrote the paper.

\section{ACKNOWLEDGMENTS}

This work was supported by grants from the Korean Health Technology R\&D Project, Ministry of Health \& Welfare, Republic of Korea (HI14C24470000) and from the National Research Foundation of Korea (NRF), funded by Ministry of Science, ICT and Future Planning (MSIP) (NRF-2014M1A3A3A02034917 and NRF2016R1A2B4011636).

\section{CONFLICTS OF INTEREST}

The authors declare no financial conflicts of interest.

\section{REFERENCES}

1. Burr DB, Gallant MA. Bone remodelling in osteoarthritis. Nat Rev Rheumatol. 2012; 8:665-73.

2. Boyle WJ, Simonet WS, Lacey DL. Osteoclast differentiation and activation. Nature. 2003; 423:337-42.

3. Danks L, Takayanagi H. Immunology and bone. J Biochem. 2013; 154:29-39.

4. Teitelbaum SL. Bone resorption by osteoclasts. Science. 2000; 289:1504-8. 
5. Boyce BF. Advances in the regulation of osteoclasts and osteoclast functions. J Dent Res. 2013; 92:860-67.

6. Rho J, Takami M, Choi Y. Osteoimmunology: interactions of the immune and skeletal systems. Mol Cells. 2004; 17:1-9.

7. Downing JR, Rettenmier CW, Sherr CJ. Ligand-induced tyrosine kinase activity of the colony-stimulating factor 1 receptor in a murine macrophage cell line. Mol Cell Biol. 1988; 8:1795-9.

8. Sengupta A, Liu WK, Yeung YG, Yeung DC, Frackelton AR Jr, Stanley ER. Identification and subcellular localization of proteins that are rapidly phosphorylated in tyrosine in response to colony-stimulating factor 1 . Proc Natl Acad Sci USA. 1988; 85:8062-6.

9. Hamilton JA. CSF-1 signal transduction. J Leukoc Biol. 1997; 62:145-55.

10. Takayanagi H. The role of NFAT in osteoclast formation. Ann NY Acad Sci. 2007; 1116:227-37.

11. Makishima M, Okamoto AY, Repa JJ, Tu H, Learned RM, Luk A, Hull MV, Lustig KD, Mangelsdorf DJ, Shan B. Identification of a nuclear receptor for bile acids. Science. 1999; 284:1362-5.

12. Parks DJ, Blanchard SG, Bledsoe RK, Chandra G, Consler TG, Kliewer SA, Stimmel JB, Willson TM, Zavacki AM, Moore DD, Lehmann JM. Bile acids: natural ligands for an orphan nuclear receptor. Science. 1999; 284:1365-8.

13. Wang H, Chen J, Hollister K, Sowers LC, Forman BM.Endogenous bile acids are ligands for the nuclear receptor FXR/BAR. Mol Cell. 1999; 3:543-53.

14. Laffitte BA, Kast HR, Nguyen CM, Zavacki AM, Moore DD, Edwards PA.Identification of the DNA binding specificity and potential target genes for the farnesoid X-activated receptor. J Biol Chem. 2000; 275:10638-47.

15. Modica S, Moschetta A.Nuclear bile acid receptor FXR as pharmacological target: are we there yet? FEBS Lett. 2006; 580:5492-9.

16. Seol W, Choi HS, Moore DD.Isolation of proteins that interact specifically with the retinoid $\mathrm{X}$ receptor: two novel orphan receptors. Mol Endocrinol. 1995; 9:972-85.

17. Forman BM, Goode E, Chen J, Oro AE, Bradley DJ, Perlmann T, Noonan DJ, Burka LT, McMorris T, Lamph WW, Evans RM, Weinberger C. Identification of a nuclear receptor that is activated by farnesol metabolites. Cell. 1995; 81:687-93.

18. Lee FY, Lee H, Hubbert ML, Edwards PA, Zhang Y. FXR, a multipurpose nuclear receptor. Trends Biochem Sci. 2006; 31:572-80.

19. Modica S, Gadaleta RM, Moschetta A.Deciphering the nuclear bile acid receptor FXR paradigm.Nucl Recept Signal. 2010; 8:1-28.

20. Wang YD, Chen WD, Huang W. FXR, a target for different diseases. Histol Histopathol. 2008; 23:621-7.

21. Cho SW, An JH, Park H, Yang JY, Choi HJ, Kim SW,Park YJ, Kim SY, Yim M, Baek WY, Kim JE, Shin CS. Positive regulation of osteogenesis by bile acid through FXR. J Bone Miner Res. 2013; 28:2109-21.
22. Sinal CJ, Tohkin M, Miyata M, Ward JM, Lambert G, Gonzalez FJ. Targeted disruption of the nuclear receptor FXR/BAR impairs bile acid and lipid homeostasis.Cell. 2000; 102:731-44.

23. Ishijima M, Rittling SR, Yamashita T, Tsuji K, Kurosawa H, Nifuji A,Denhardt DT, Noda M. Enhancement of osteoclastic bone resorption and suppression of osteoblastic bone formation in response to reduced mechanical stress do not occur in the absence of osteopontin. J Exp Med. 2001; 193:399-404.

24. Wan Y. PPAR $\gamma$ in bone homeostasis. Trends Endocrinol Metab. 2010; 21:722-8.

25. Wan Y, Chong LW, Evans RM.PPAR $\gamma$ regulates osteoclastogenesis in mice.Nat Med. 2007; 13:1496-1503.

26. Lelliott CJ, Vidal-Puig A. PGC-1beta: a co-activator that sets the tone for both basal and stress-stimulated mitochondrial activity. Adv Exp Med Biol. 2009; 646:133-9.

27. Scarpulla RC. Metabolic control of mitochondrial biogenesis through the PGC-1 family regulatory network. Biochim Biophys Acta. 2011; 1813:1269-78.

28. Liu C, Lin JD. PGC-1 coactivators in the control of energy metabolism. Acta Biochim Biophys Sin (Shanghai). 2011; 43:248-57.

29. Leone TC, Kelly DP. Transcriptional control of cardiac fuel metabolism and mitochondrial function. Cold Spring Harb Symp Quant Biol. 2011; 76:175-82.

30. Wu H, Li L, Ma Y, Chen Y, Zhao J, Lu Y, Shen P. Regulation of Selective PPAR $\gamma$ modulators in the differentiation of osteoclasts. J Cell Biochem. 2013; 114:1969-77.

31. Takayanagi H, Kim S, Matsuo K, Suzuki H, Suzuki T, Sato K, Yokochi T, Oda H, Nakamura K, Ida N, Wagner EF, Taniquchi T. RANKL maintains bone homeostasis through c-Fos-dependent induction of interferon- $\beta$. Nature. 2002; 416:744-9.

32. Xiong Q, Zhang L, Ge W, Tang P. The roles of interferons in osteoclasts and osteoclastogenesis. Joint Bone Spine. 2016; 83:276-81.

33. Wang Y, Liu W, Masuyama R, Fukuyama R, Ito M, Zhang Q, Komori H, Murakami T, Moriishi T, Miyazaki T, Kitazawa T, Yoshida CA, Kawai Y, et al. Pyruvate dehydrogenase kinase 4 induces bone loss at unloading by promoting osteoclastogenesis. Bone. 2012; 50:409-19.

34. Davis RJ. Signal transduction by the JNK group of MAP kinases. Cell. 2000; 103:239-52.

35. Chang EJ, Ha J, Huang H, Kim HJ, Woo JH, Lee Y, Lee ZH, Kim JH, Kim HH. The JNK-dependent CaMK pathway restrains the reversion of committed cells during osteoclast differentiation. J Cell Sci. 2008; 121:2555-64.

36. David JP, Sabapathy K, Hoffmann O, Idarraga MH, Wagner EF. JNK1 modulates osteoclastogenesis through both c-Jun phosphorylation-dependent and -independent mechanisms. J Cell Sci. 2002; 115:4317-25.

37. Wei W, Wan Y. Thiazolidinediones on PPAR $\gamma$ : The roles in bone remodeling. PPAR Res. 2011; 2011:1-9.

38. Ahmadian M, Suh JM, Hah N, Liddle C, Atkins AR, Downes M, Evans RM. PPAR $\gamma$ signaling and metabolism: the good, the bad and the future. Nat Med. 2013; 19:557-66. 
39. Wei W, Wang X, Yang M, Smith LC, Dechow PC, Sonoda J, Evans RM, Wan Y. PGC1beta mediates PPAR-gamma activation of osteoclastogenesis and rosiglitazone-induced bone loss. Cell Metab. 2010; 11:503-16.

40. Ishii KA, Fumoto T, Iwai K, Takeshita S, Ito M, Shimohata N, Aburatani H, Taketani S, Lelliott CJ, Vidal-Puig A, Ikeda K.Coordination of PGC-1beta and iron uptake in mitochondrial biogenesis and osteoclast activation. Nat Med. 2009; 15:259-66.

41. Rozo AV, Vijayvargia R, Weiss HR, Ruan H.Silencing Jnk1 and Jnk2 accelerates basal lipolysis and promotes fatty acid re-esterification in mouse adipocytes. Diabetologia. 2008; 51:1493-504.
42. Takayanagi H, Ogasawara K, Hida S, Chiba T, Murata S, Sato K, Takaoka A, Yokochi T, Oda H, Tanaka K, Nakamura K, Taniquchi T. T-cell-mediated regulation of osteoclastogenesis by signalling cross-talk between RANKL and IFN-gamma. Nature. 2000; 408:600-5.

43. World Population Ageing 2013. United Nations, Department of Economic and Social Affairs, Population Division. 2013. ST/ESA/SER.A/348. 